Robson, Benjamin Aubrey, et al. "Automated classification of debris-covered glaciers combining optical, SAR and topographic data in an object-based environment." Remote Sensing of Environment 170 (2015): 372-387.

(c) 2015. This manuscript version is made available under the CC-BY-NC-ND 4.0 license http://creativecommons.org/licenses/by-nc-nd/4.0/ 


\section{Automated classification of debris-covered glaciers combining optical, SAR and topographic data in}

\section{an object-based environment}

ROBSON, Benjamin Aubrey ${ }^{a^{*}}$, NUTH, Christopher ${ }^{b}$, DAHL, Svein Olaf ${ }^{a}$, HÖLBLING, Daniel ${ }^{c}$, STROZZI, $^{2}$ Tazio $^{\mathrm{d}}$, and NIELSEN, Pål Ringkjøb ${ }^{\mathrm{a}}$

(a) University of Bergen, Norway (b) University of Oslo, Norway, (c) University of Salzburg, Austria (d) GAMMA Remote Sensing, Switzerland

* Corresponding author at: Department of Geography, University of Bergen, Fosswinckelsgate 6, 5007Bergen, Norway. Tel: +47 5558 3077. Email address: benjamin.robson@uib.no

2 Christopher Nuth, Department of Geosciences, University of Oslo, Postboks 1047 Blindern, Oslo, 0316, Norway. Tel: +47 22855836. Email address: christopher.nuth@geo.uio.no

3 Svein Olaf Dahl, Department of Geography, University of Bergen, Fosswinckelsgate 6, 5007Bergen, Norway. Tel: +47555830 65. Email address: Svein.Dahl@uib.no

4 Daniel Hölbling, Department of Geoinfomatics -Z_GIS, University of Salzburg, Schillerstrasse 30, 5020 Salzburg, Austria. Tel: +43 6628044 7581. Email address: daniel.hoelbling@sbg.ac.at

5. Tazio Strozzi, GAMMA Remote Sensing, Worbstr. 225, Gümligen, 3073, Switzerland. Tel: +41 31 951 7005. Email address: strozzi@gamma-rs.ch

5. Pål Ringskøb Nielsen, Department of Geography, University of Bergen, Fosswinckelsgate 6, 5007 Bergen, Norway. Tel: +475558 3077. Email address: Pal.R.Nielsen@uib.no 


\section{Abstract}

21 Satellite imagery is increasingly used to monitor glacier area changes and create glacier inventories.

Robust and efficient pixel-based band ratios have proven to be accurate for automatically delineating clean glacier ice, however such classifications are restricted by debris-covered ice due to its spectral similarity with surrounding terrain. Object-Based Image Analysis (OBIA) has emerged as a new analysis technique within remote sensing. It offers many advantages over pixel-based classification techniques due to the ability to work with multiple data sources and handle data contextually and hierarchically. By making use of OBIA capabilities we automatically classify clean ice and debriscovered ice in the challenging area surrounding Mount Manaslu in Nepal using optical (Landsat 8), topographic (void-filled SRTM) and SAR coherence (ALOS PALSAR) data. Clean ice was classified with a mean accuracy of $93.3 \%$ while debris-covered ice was classified with an accuracy of $83.3 \%$ when compared to manually corrected outlines, providing a total glacier accuracy of $91 \%$. With further developments in the classification, steep tributary sections of ice could be contextually included, raising the accuracy to over $94 \%$. One prominent advantage of OBIA is that it allows some postprocessing and correction of the glacier outlines automatically, reducing the amount of manual correction needed. OBIA incorporating SAR coherence data can be recommended for future mapping of debris-covered ice.

Keywords: Debris-covered glacier, object-based image analysis, Landsat 8, SAR coherence, semi- 


\section{Introduction}

40

41

Current and accurate glacier outlines are required for many applications within glaciology, such as glacier area change analysis (Nuth et al., 2013, Bajracharya et al., 2014a, Shangguan et al., 2014), masks when determining glacier velocity (Berthier et al., 2005, Kääb, 2005, Quincey et al., 2009) and volume change estimations (Berthier et al., 2010, Gardelle et al., 2013), as well as input and validation data within glacier modelling (Rees and Collins, 2006, Racoviteanu et al., 2013, Pradhananga et al., 2014).

Due to their remote location, many glaciated areas, such as the Himalayas, are under-sampled when it comes to direct in-situ glacier observation data (Berthier et al., 2007). Existing in-situ data is often biased towards small to medium sized and debris-free glaciers(Gardelle et al., 2013). Mass balance measurements are relatively sparse and cover less than 10 years, (Bolch et al., 2012)

The status of glaciers within the Himalayas is of great importance. Changes in glaciated area have implications on the amount of ice area exposed to melt, this influencing the discharge of many rivers originating in the Himalayas that are important for irrigation and hydroelectric power production (Immerzeel et al., 2010, Bolch et al., 2012). Additionally, the continued down-wasting and retreat of debris-covered glaciers in the Himalayas can lead to the development of moraine-dammed lakes, which can breach catastrophically producing glacial lake outburst floods (GLOFs) that disrupt downstream populations and infrastructure (Richardson and Reynolds, 2000).

Remotely sensed data provide a means of increasing our understanding of these remote regions by permitting analysis at the regional scale (Paul et al., 2013c, Nuimura et al., 2014). Satellite imagery has been widely used in the last decades for delineating glacier outlines over large areas, often using automated or semi-automated methodologies such as band ratios and supervised classifications, with reported accuracies of over 95\% (Albert, 2002, Paul and Andreassen, 2009, Paul et al., 2013a). Global glacier inventories such as the GLIMS (Global Land Ice Measurements from Space) initiative 
and the Randolph Glacier Inventory aim to map land glaciers globally using optical satellite imagery and assess their changes over time (Ranzi et al., 2004, Pfeffer et al., 2014). The application of these techniques has allowed glaciers to be mapped and analysed over large areas of the Himalayas (Scherler et al., 2011, Frey et al., 2012, Bajracharya et al., 2014b, Nuimura et al., 2014).

Many glaciers within the Himalayas are covered in heavy debris cover. Debris-cover on glacier-ice is an important component in glacier mass balance and is known to complicate the response of the ice to climate (Scherler et al., 2011, Zhang et al., 2011, Benn et al., 2012, Pratap et al., 2015), yet the relationship is poorly understood. Debris cover can act to either insulate or amplify glacial melting, depending on variables such as the debris thickness and composition and the amount of precipitation (Takeuchi et al., 2000, Reznichenko et al., 2010, Bhardwaj et al., 2014a). For example Bolch et al. (2008a) reported that the debris coverage on Khumbu Glacier increased as the total glacier area reduced. The spatial distribution of debris over the glacier and the presence of supraglacial lakes and exposed ice cliffs are therefore important factors affecting how the glacier responds to changes in climate. In some cases, debris cover may cause rates of ablation to increase by up to an order of magnitude (Benn et al., 2012, Immerzeel et al., 2014, Juen et al., 2014).

Although the delineation of clean ice is a robust and accurate procedure, the automated classification of debris-covered glacier ice is not so straightforward, due to the spectral similarity of glacier debris cover to the surrounding terrain of rock or glacial moraines (Paul et al., 2013c, Huang et al., 2014). Several methods have been implemented to aid delineation of debris-covered ice. Morphological parameters such as the slope and curvature, as well as thermal satellite data have been used in both automatic and semi-automatic classification methods (Paul et al., 2004, Ranzi et al., 2004, Bolch et al., 2007, Shukla et al., 2010, Bhambri et al., 2011, Racoviteanu and Williams, 2012, Tiwari et al., 2014). To date however, most of these automated studies have not focused on largescale regions $\left(>200 \mathrm{~km}^{2}\right)$ but a small number of glaciers ( $<5$ glaciers) are analysed e.g. (Bolch et al., 2007, Bhambri et al., 2011, Racoviteanu and Williams, 2012, Bhardwaj et al., 2014b). A high 
resolution Digital Elevation Model (DEM) significantly aids the automated delineations of debriscovered ice through topographic parameters such as curvature or slope (Tiwari et al., 2014), yet DEMs over many mountainous areas often have high uncertainty, with high-resolution DEMs often only available at great expense (Bolch et al., 2007). The majority of studies that delineate debriscovered glaciers therefore have relied on some degree of manual interpretation (Bajracharya and Shrestha, 2011, Sharma et al., 2013, Bhardwaj et al., 2014b, Kääb et al., 2014, Nuimura et al., 2014, Shangguan et al., 2014). Paul et al. (2013a) had 20 participants manually map 24 glaciers and found differences in interpretation of up to $30 \%$ over heavily debris-covered glaciers. One reason for this is the high variability in the spatial coverage and composition of glacial debris cover, which makes spectral and topographic delineations difficult (Racoviteanu et al., 2009).

Some recent studies have exploited the coherence pattern between two Synthetic Aperture Radar (SAR) images in order to differentiate debris-covered ice from surrounding terrain (Zongli et al., 2011, Frey et al., 2012, Saraswat et al., 2013, Snehmani et al., 2014). Change over time results in a loss of coherence over the glacier, which can then be used as a guide for the digitisation of debris-covered ice (Frey et al., 2012). Atwood et al. (2010) automatically mapped debris-covered ice in the Wrangell Mountains and the Juneau Ice Field in Alaska, relying solely on SAR coherence data. Complicated mountain topography however makes this unfeasible in regions such as the Himalayas where layover and foreshortening can cause no signal return to the sensor over sizable areas (Frey et al., 2012).

Object-Based Image Analysis (OBIA) is a promising methodology where near-homogenous objects are the basis of classifications instead of pixels. This allows more possibilities when defining classification rules, e.g. considering spatial characteristics or context information. OBIA also allows multi-data integration meaning that it is possible to fully exploit a combination of data sources, (e.g. optical satellite imagery, SAR data, DEM). OBIA can therefore be used to semi-automatically classify glaciers and distinguish between different surface types and characteristics. 
The main objective of this study is to test OBIA for accurately delineating debris-covered glaciers by combining SAR coherence data with optical and topographic data. The accuracy of the classification technique is assessed by comparing the automatic outlines against both manually delineated outlines, and the most recent published glacier outlines available at the time of study. For most of the study area the International Centre for Integrated Mountain Development (ICIMOD) glacier inventory was used. This inventory was based on images acquired between 2007 and 2009 for glaciers in Nepal. The glacier outlines in Tibet are from the Chinese Glacier Inventory (CGI) based on aerial photography from the 1970s. Both glacier inventories were downloaded through the GLIMS database. (ICIMOD, 2010, GLIMS, 2014). For simplicity we refer to both glacier inventories as the reference outlines for the duration of the paper.

\subsection{Study Area}

We tested our classification in the Manaslu region of Nepal. The Manaslu Region was chosen due to both the assortment and range of glaciers found under various conditions (clean ice, heavily debriscovered, stagnant ice, lake terminating ice) and its accessibility from Kathmandu. The region covers $2350 \mathrm{~km}^{2}$ in total. The glaciers in the study area range in elevation from 3000 m.a.s.l. to over 7000 m.a.s.l and cover a combined area of $788 \mathrm{~km}^{2}$. They are typically $0.5-1 \mathrm{~km}$ in width and $5-15 \mathrm{~km}$ in length with areas that vary from $5.6 \mathrm{~km}^{2}$ to $32.0 \mathrm{~km}^{2}$. The glaciers on the southern side of the topographic divide are heavily debris-covered, while those north of the divide are clean type glaciers, with minimal or no debris cover. Nineteen debris-covered glaciers are analysed in the vicinity of Mount Manaslu (8163 m), which lies between the districts of Gorkha and Manang in Central Nepal, (Figure 1). Ten clean-ice glaciers on the northern slopes of Himlung, Ratna Chuli and Lugula Himal were also investigated. The Manaslu Region is situated at the boundary between the maritime, monsoon-driven climate found in Nepal, and the drier, more continental climate of the Tibetan plateau (Benn and Owen, 1998). Although climate data is limited, the Nepali Department of Hydrology and Meteorology estimate maximum and minimum temperatures of $26.7^{\circ} \mathrm{C}$ and $12.8^{\circ} \mathrm{C}$ 
with $1066 \mathrm{~mm}$ of precipitation a year at the weather station Larke Samdo, $84^{\circ} 38 \mathrm{E}, 28^{\circ} 39 \mathrm{~N}, 3650$

m.a.s.I. (Government of Nepal, 2014). Glaciers in Nepal receive up to $80 \%$ of their annual accumulation during the summer monsoon between June and September (Ageta and Higuchi, 1984, Benn and Owen, 1998). Rates of both accumulation and ablation are highest simultaneously during the summer monsoon; small changes in temperature can therefore strongly affect the balance between accumulation and ablation (Benn and Owen, 1998). Glaciers on the northern side of the mountain divide receive much less precipitation, and as such respond primarily to changes in ablation season temperature (Owen and Benn, 2005). A combination of warmer summer temperatures and reduced precipitation over the last few decades have caused increased rain and reduced snow, (Benn et al., 2012) leading to a marked retreat of many glaciers within the Himalayas (Bajracharya et al., 2014a).

The study area also contains Thulagi Lake $\left(0.9 \mathrm{~km}^{2}\right)$, (also referred to as Dona Lake) situated in front of Thulagi Glacier (G084538E28524N); which has been identified as one of the most potentially hazardous glacial lakes in Nepal (Mool et al., 2011). An outburst flood could affect 160,000 people in the Marsyangdi river basin, damaging or destroying infrastructure relating to hydroelectric power generation as well as sections of the Annapurna and Manaslu hiking circuits (Mool et al., 2011).

\section{Background}

\subsection{Object-Based Image Analysis}

Object-based image analysis (OBIA) is a spatially explicit information extraction workflow, combining image processing and GIS functionalities (Blaschke, 2010). Traditional pixel-based methods only consider the spectral characteristics of single pixels, often resulting in a salt-and-pepper effect within the classification, thus requiring post-processing or cleaning. This reduces the robustness of pixelbased methods to adequately depict complex natural phenomena such as glaciers. In addition, pixels may not always be clearly assignable to one land cover type since each pixel can contain reflectance 
values from multiple land classes. OBIA instead segments pixels into near-homogenous objects, on which the analysis is conducted.

OBIA provides a methodological framework for computer-based interpretation of complex classes that are defined by a range of spatial, spectral and contextual properties derived from multiple data sources (Lang, 2008). Today, OBIA or GEOBIA (geographic object-based image analysis) is a relatively new and evolving methodology in remote sensing and GIScience (Blaschke et al., 2014). Working on the object-level as opposed to the pixel-level facilitates the combined use of spectral, spatial, textural, hierarchical and contextual properties. Unlike single pixels, image objects are defined by a large number of properties in addition to just spectral values, such as shape, compactness and area that can be applied during classification. This is especially useful when working with high resolution (HR) imagery (spatial resolution $<30 \mathrm{~m}$ ) or very high resolution (VHR) imagery (spatial resolution $<4$ m),(Hoersch and Amans, 2012) where objects of interest are usually larger than the pixel size, or when performing combined analysis of data from various sources (e.g. optical, DEM, SAR, vector data) as the most appropriate properties of image objects derived from multiple datasets can be used for classification. This makes object-based approaches more intricate, especially when performing knowledge-based analysis. The process of how scene complexity is broken down into meaningful image primitives with object-based approaches is closely related to how humans perceive an image (Blaschke and Strobl, 2001). Extracting useful information from individual pixels can be significantly influenced by the signals of surrounding pixels (Townshend et al., 2000). This effect can be almost neglected when working with image objects because of the reduced relevance of radiometric information of single pixels. For the same reason, atmospheric and radiometric correction of images appear to be less important for object-based mapping tasks (Hölbling et al., 2015). A number of studies have shown that OBIA outperforms pixel-based approaches within various applications such as land use mapping and landslide delineation (Gao et al., 2006, Myint et al., 2011, Moosavi et al., 2014). 
188

189

190

191

192

193

194

195

196

197

198

199

200

201

202

203

204

205

206

207

Initial studies have been conducted delineating debris-covered ice within an object-based classification. Rastner et al. (2014), for example compared pixel-based and object-based classification techniques with high reliance on slope and surface temperature parameters over different clean and debris-covered conditions. They found object-based classifications delivered marginally more accurate results when classifying clean ice, but significantly more accurate results when working on debris-covered ice. The International Centre for Integrated Mountain Development (ICIMOD) used Landsat TM and SRTM elevation data within OBIA to classify glaciers over the entire Himalayas (ICIMOD, 2010, Bajracharya and Shrestha, 2011, Bajracharya et al., 2014a, Bajracharya et al., 2014b), although the amount of manual correction required is not known.

\subsection{Use of Remote Sensing data to classify glaciers}

This study uses optical, topographic and SAR coherence data. The background and how each dataset can be used to detect glacier ice are detailed below.

Due to the high spectral contrast between clean ice and the surrounding terrain, optical images provide a reliable means of automatically classifying clean ice. Band ratios have been found to be the most consistently accurate way of classifying clean ice (Albert, 2002), with a threshold applied to ratios of the Landsat TM bands TM 4/TM 5 or TM3/TM5 being the most accurate and robust (Paul et al., 2013b).Much work has been done mapping debris-covered ice using optical data. Band ratios such as the NDVI, LWM and NDSI (explained in ) have been used to debris-covered glaciers (Keshri et al., 2009, Bajracharya et al., 2014b, Bajracharya et al., 2015). Brenning et al. (2012) on the other hand used the diurnal variation in thermal data to map glaciers. Most authors however have combined SWIR, NIR and thermal band data for mapping debris-covered ice (Shukla et al., 2010, Casey et al., 2012, Karimi et al., 2012, Bhardwaj et al., 2014b, Tiwari et al., 2014, Alifu et al., 2015). We investigated the potential of including thermal data in our study; however the thermal signature was not consistently visible over the study area. While some debris-covered glaciers exhibited a clear 
difference in temperature, for many of the debris-covered glaciers there was no thermal signature visible through the glacier debris. We therefore did not include thermal data in the classification.

As mentioned above, breaks in topographic data such as surface slope and curvature can be used to distinguish the debris-covered glacier tongue morphologically (Bolch et al., 2007), while elevation can constrain the altitudinal extent of classifications to exclude false positives.

The de-coherence between two SAR radar images acquired with a time interval between them relates to either motion occurring between when the images were taken, or to changing surface conditions. It is therefore important to distinguish glaciers from changing surface conditions, such as snowfall, rock slides and vegetation changes (Snehmani et al., 2014). The use of SAR coherence data is therefore appealing as it provides a way to distinguish moving debris-covered glacier areas that are optically similar to the surrounding non-glacier terrain. The integration of SAR data with optical images and digital elevation information in OBIA can provide valuable information for classification. The exploitation of interferometric coherence information between two SAR images separated by a time interval provides a means of identifying features that have changed in a landscape (Strozzi et al., 2000), and as such is applicable to the study of features such as glaciers and landslides (Catani et al., 2005, Atwood et al., 2010, Joyce et al., 2014).

Optical or topographic data are incapable of differentiating between active glacier-ice and stagnant glacier ice, something that Bolch et al. (2007) and Ghosh et al. (2014) state as a weakness in current methods for classifying debris-covered ice. SAR coherence data allow the identification of active ice based on whether motion or a change in surface conditions has occurred. There is some discussion however whether stagnant glacier tongues should be included in glacier mapping. Many definitions of what constitutes a glacier specifically mention that glaciers must be actively flowing (Kääb, 2005, Benn and Evans, 2010, Cuffey and Paterson, 2010). However if one is interested in GLOF hazards, then the downwasting of stagnant ice is very important (Richardson and Reynolds, 2000, Bolch et al., 2008b). It is beyond the scope of this paper to speculate whether stagnant glacier-ice should be 
237 included or not in glacier mapping; however in this stidu we only consider debris-covered ice that is

238 active.

2392 Data and Methods

\subsection{Data}

Optical imagery from Landsat 8 (Green, Red, NIR and SWIR-1 bands) acquired in October and

December 2013 was used. One Landsat 8 scene from October was used for debris-covered glaciers,

while a second scene from late December was used on the higher elevation, clean-ice and the

glaciers in the north of the study area which were affected by seasonal snow in the October scene. In

addition, a RapidEye image (5 metre resolution) was used to manually correct the glacier outlines.

The elevation data used in the classification is a version of the SRTM DEM that that was void-filled with the 1:50 000 Finnmap topographic maps of Nepal (available pre-processed online (De Ferranti, 2012)). The ASTER GDEM was not used as it is considerably noisy; contains large striping artefacts (Tachikawa et al., 2011, Rexer and Hirt, 2014) and lacks a consistent timestamp that would have led to problems when classifying with topographic derivatives. days. All the data used in this study is shown in .

\begin{tabular}{|l|l|l|l|}
\hline & & & \\
\hline & & & \\
\hline & & & \\
\hline & & & \\
\hline & & & \\
\hline & & & \\
\hline
\end{tabular}


The OBIA procedure was performed within Trimble eCognition 9.0. Two classifications were performed: one based solely on the optical and topographic data (OBIA_OT), while the second classification used in addition the SAR coherence images (OBIA_OTS).

The workflow consists of three steps:

1. Pre-processing: The SRTM was bi-linearly resampled to $30 \mathrm{~m}$ resolution to match the resolution of the Landsat 8 image and a slope raster generated. Custom indices and band ratios were created () within ArcGIS.The ALOS PALSAR images were processed in order to create the SAR Coherence data. First, the interferometric processing combined the pairs of Single Look Complex (SLC) images at HH-polarization into interferograms using GAMMA Remote Sensing software. Because of rugged topography in some areas, a simulated phase image, which corresponds to the topographic phase was computed from the void-filled SRTM DEM and then subtracted from the interferometric phase. For coherence estimation an adaptive window size varying between $3 \times 3$ and $9 \times 9$ pixels for a 1 range $\times 4$ azimuth looks interferogram was used (Frey et al, 2012). The resulting terrain-corrected and geocoded coherence images were combined with a mask considering regions with layover and radar shadow as well as the SRTM voids. The two coherence images were mosaicked into one file for input into OBIA. All data was projected to UTM zone 45N.

2. Image segmentation: The initial image segmentation into near-homogeneous objects is one of the most critical stages within OBIA (Drăguţ et al., 2014). Image segmentation is a bottomup process that begins by grouping pixels into objects. Additional object hierarchical levels can be created where individual objects are merged. Different datasets (individual spectral bands, topographic derivatives, etc.) can be used to segment the image, and different weighting factors based on their importance in the segmentation can be assigned. As pointed out by Rastner et al. (2014), the performance of OBIA is strongly influenced by the initial choice of parameters during image segmentation. A trade-off had to be reached between 
creating too large and too small objects. The former can cause multiple classes to be grouped into single objects, resulting in misclassifications, while the latter reduces the functionality of using shape and contextual constraints in the classification. In both classifications, image objects were created using the multi-resolution segmentation algorithm in eCognition based on three hierarchical levels on the blue, green, NIR, panchromatic, red and shortwave infrared bands, as well as the slope. It was found that having multiple image object levels helped group non-glacier features together, making it easier to exclude them from the classification. For the classification that incorporated SAR data, the SAR coherence data was also included. The scale parameter, which dictates the size of objects, was chosen with assistance from the Estimation of Scale Parameter 2 (ESP 2) tool (Drăguţ et al., 2014). The scale parameter, shape and compactness criterions used are displayed in Figure 2..

3. Rule based classifications: Figure 2 shows the workflow for the classification procedure, including all parameters and thresholds that were used, as well as the post-classification filtering. Various parameters and parameter combinations (band ratios and indices, topographic derivatives, spatial properties, etc) were tested to determine the most appropriate thresholds and parameters for classification. Some thresholds were acquired from literature (for example the SWIR/NIR ratio, NDVI and slope) (Paul et al., 2013b, Bajracharya et al., 2014a) while others were determined through trial and error. Fuzzy logic classifications were used to identify lakes, clean ice and debris-covered ice. Fuzzy logic relies on assigning membership functions to different criteria ranging from 0 (non-member) to 1 (member) (Benz et al., 2004). In addition, each classification rule was assigned a weighting 

the classification.

The following classification procedure was applied: could be masked out for the rest of the analysis. Water bodies were classified using the NDWI, slope and elevation. Clean ice was classified using the Landsat NIR/SWIR1 ratio, slope and elevation.

\section{3b. Mapping of Debris-covered Ice}

A third segmentation level was applied to all unclassified objects. This was found to help group non-glacier objects. The following two classifications were then performed.

\section{i. Classification using only optical and elevation data (OBIA_OT)}

Debris-covered ice was classified with greater weight on the NDVI, NDSI and slope.. Similar to Bajracharya et al. (2014a), the elevation was used to limit the altitudinal range where glaciers could be classified, reducing false positives. The LWM was also included in the classification.

\section{ii Classification using SAR Coherence data (OBIA_OTS)}

The second OBIA classification procedure was much the same as the classification the NDVI and NDSI. 
4. Classification refinement: The image objects classified as glacier ice were merged together, and then objects were filtered by area and by the distance from the clean ice. The image objects were then expanded into neighbouring objects with similar spectral, topographic or SAR coherence characteristics. Some problems were caused by very elongated but narrow objects that resulted in overestimations of the glacier width, and so for this reason a criterion was set to exclude objects that were adjacent to the debris-covered ice and had a high length/width ratio.

Lastly, object boundaries were smoothed by using the pixel-based growing and shrinking commands within eCognition. The classifications were then exported to shapefile (.shp) format.

5. Manual Correction of glacier outlines: The shapefiles were divided into drainage areas using the SRTM DEM. Due to the coarse resolution of the DEM, some manual correction was necessary for the drainage divides. The OBIA_OTS outlines were manually corrected with reference to high resolution Google Earth imagery, a RapidEye image from 2012, photographs from the field, and the SAR coherence images. Both the classifications outlines were then compared to each other, to the manually delineated outlines, and to the reference glacier inventory, which had been submitted to the Randolph Glacier Inventory (RGI 3.2) and can be downloaded online (Arendt et al., 2012, Pfeffer et al., 2014).

\section{Comparison of glacier outlines and accuracy assessment}

Originally it was planned to compare the OBIA outlines only against the reference glacier inventory for data verification, however such comparisons were not straightforward due to the range in years that were used when the reference inventory was produced. To assess the spatial overlap between the reference and the classification, our OBIA outlines were therefore compared against both the reference outlines as well as OBIA outlines that we manually corrected (OBIA_Man). For comparison purposes the reference outlines were manually split into clean ice and debris-ice by overlaying them on the Landsat images. Unlike 
the reference glacier outlines; our manual outlines used the SAR coherence data in addition to Google Earth and RapidEye imagery in order to determine the extent of the glacier ice beneath the debris cover. We therefore consider our manually corrected outlines to be sufficiently accurate to be used as "truth" in this study. The OBIA outlines, both from optical and topographic data (OBIA_OT), as well as those from optical, topographic and SAR coherence data (OBIA_OTS) were compared with the manually corrected outlines (OBIA_Man) and the reference glacier inventory (REF) and percentages of deviation were used to assess the accuracy. OBIA_Man and REF were also compared. 
359

360

361

362

363

364

365

366

367

368

369

370

371

372

373

374

375

376

377

378

379

380

A total of 19 debris-covered and 10 clean-ice glaciers were classified, comprising in total $788 \mathrm{~km}^{2}$ of ice, 15\% (113 $\left.\mathrm{km}^{2}\right)$ of which is debris-covered. Figure 3 and Table A1 show the reference glacier inventory areas (REF), the OBIA outlines using optical and terrain data (OBIA_OT), the OBIA outlines using optical, terrain and SAR Coherence data (OBIA_OTS) and the manually corrected outlines (OBIA_Man). It is apparent from Figure 3 that the OBIA_OT method has the greatest variance of the 3 methods for mapping debris-covered ice. It also appears that the mapping becomes less reliable for the larger debris-covered glaciers. Figure 4 compares both the clean ice and debris-covered ice areas derived from the OBIA method, the manual delineations and the reference glacier inventory.

In terms of total glacier area (clean ice and debris-covered ice), our method achieved an accuracy of $91.01 \%$ over the $788 \mathrm{~km}^{2}$ of glacier ice. Of the 27 glaciers classified, 14 of which were mapped with accuracy of $95 \%$ of more. While most comparable studies assess accuracy over the entire glacier due to the difficulty of classifying debris-covered ice as opposed to clean ice, we present separate results and discussion for both clean ice and debris-covered ice to quantify the difference between classification techniques used in this study.4.1 Delineation of Clean ice

Due to the high spectral contrast between ice and rock, the SAR coherence was not necessary when classifying clean ice. Comparison of the outlines from this study revealed that the clean ice areas were mapped with an accuracy of $84.7 \%$ against the reference data, and an accuracy of $93.3 \%$ against the manually corrected outlines by $6.7 \%$. This is approximately in line with the accuracies found by other studies (Paul et al., 2013c). Visual inspection of the automatic outlines reveal an accuracy of within $\pm 30 \mathrm{~m}$ within most cases. Errors arose due to shadow covering portions of the glacier and in some cases narrow strips of rock surrounded by ice were classified as glacier.

Because the reference outlines north of the mountain divide were created using aerial imagery from the 1970s, large disparities are found when compared with the automated clean ice outlines (Figure 

of glacier extent by between 500 and $1000 \mathrm{~m}$ at the glacier terminus are common.

\subsection{Delineation of Debris-covered ice}

385

386

387

Debris-covered ice remains one of the most troublesome aspects of remote sensing glaciology (Kääb et al., 2014). For debris-covered glaciers, OBIA_OTS classification mapped to an accuracy of $83.8 \%$ from the manually delineated outlines. The OBIA_OT classification is considerably less accurate, and in particular is sensitive to lithological changes in glacier debris, occasionally mapping individual glaciers as multiple entities (Figure 6). The mean accuracy falls to $71.7 \%$ when compared to the manual delineations. This is a sizable error term, and shall be explored in the following section.

Both object-based classifications fail to detect debris-covered ice in some situations. Neither method fully classifies the steep tributaries of clean ice that flow down gullies towards the glacier. The steepness of these sections, often $25-50^{\circ}$, and therefore above the threshold of $14-16^{\circ}$ used for debris-covered ice, as well as the area of individual objects means that they are excluded from the classification. When the slope threshold was increased to accommodate these steep sections it was found to include non-glacial debris adjacent to the glacier terminus. If these steep tributaries of ice are excluded from the accuracy assessment then the accuracy of mapping debris-covered ice rises to $90.8 \%$, over the entire glacier this raises the accuracy to $94 \%$. This shows that if the classification procedure can be improved to contextually include these areas then the OBIA method has a large potential for future application.

On occasion there are areas where the reference outlines fail to map debris-covered ice, for example the glacier termini are often not fully mapped (as visible in Figure 6D and Figure 7). highlighting problems caused by the spectral similarity of debris-covered ice to the surrounding terrain for mapping debris-covered ice without additional data. Moreover, in some areas steep marginal moraines or paraglacial slopes are misclassified as debris-covered ice (Figure 6) by both classification techniques, although glacier ice can extend into valley slopes by up to $100 \mathrm{~m}$ (Bernard et al. (2014)). 
407 If the OBA_OTS outlines are compared to the manual delineations solely on the glacier margins and

408 termini, thereby excluding the steep upper reaches the classifications struggle with (Table A2), the 409 error reduces to $9.2 \%$ over debris-covered ice, or $6 \%$ over the total glacier area. This shows that further development of the methodology within OBIA addressing these steep portions of ice through contextual properties could lift the accuracy of the delineations of debris-covered ice over large regions to over $94 \%$.

4.3 Comparison of SAR coherence based classification (OBIA_OTS) to spectral based classification (OBIA_OT)

The OBIA_OTS outperforms the OBIA_OT classification in most cases, especially on the glacier termini, where the glacier debris often becomes more lithologically similar to the surrounding bedrock (Kääb et al., 2014). In cases where the OBIA_OT outperforms the OBIA_OTS classification it does so mostly by a narrow margin - $3.2 \%$ compared to the $18.2 \%$ that the OBIA_OTS classification on average outperforms the OBIA_OT classification. The SAR based classification occasionally delineated what appeared to be avalanche or debris flow deposits which flow out onto the glacier. Similarly, in a few situations (for example on glacier G084374E28756N) the OBIA_OT classification was able to differentiate between the debris-covered ice and paraglacial slopes better than the OBIA_OTS classification. This can most likely be explained by the paraglacial slopes and glacier debris being more lithologically distinct in the optical imagery compared with in the SAR coherence data. 
The OBIA_OTS classification however was able to classify the glacier on relative motion and not just based on the debris lithology. Even in situations where the lithology was sufficiently distinct between the debris and rock, the heterogeneity of image objects based on optical data still occasionally caused misclassifications towards the glacier margins.

There were some areas where the SAR coherence data had problems, for example a loss of coherence over water(Figure 8A), steep north-facing valleys (Figure $8 \mathrm{~B}$ ), or areas where no data was received back at the sensor (Figure $8 \mathrm{C}$ ). Problems can arise through orthorectification of the SAR data, or areas with non-uniform patterns of SAR coherence, for example at some of the glacier termini which confused the classification.

\section{Discussion}

\section{Discussion}

\subsection{Comparison with other debris-covered ice classifications.}

The accuracy of a glacier outline is dependent upon a number of factors, for example the presence of seasonal snow and shadows, the identification of topographic drainage divides and the presence of supraglacial debris (Paul et al., 2013a). Often the accuracy is provided as a percentage of the total glacier area as this is one of the only measures from which to compare various studies on various glaciers. However, the relative accuracy is dependent significantly on the size of the glacier or study area, and thus comparisons to other studies must also consider this. As the study area or number of glaciers mapped increases, the error term becomes more random and less systematic (Nuth et al., 2013). Care must therefore be taken then when comparing accuacy assessments between studies, especially for studies that worked on a few large glaciers.

\section{There are very few studies that have used OBIA to directly map glacier ice. Rastner et al. (2014)} mapped glaciers in Everest Region of Nepal and similarly found that OBIA mapped debris-covered ice $11.9 \%$ more accurately than pixel based methods, with an overall accuracy of $88.5 \%$, however no 
4702 Although some studies obtained higher accuracies than us, their study areas were considerably

471 smaller, and any automatic method for mapping debris-covered ice should function over large areas.

472 We therefore consider our method as favourable due to its inclusion of SAR data which is used to

473 distinguish active-ice from stagnant-ice, and its application over a large study area, despite the

474 slightly lower accuracies found. 


\subsection{Use of SAR coherence data to classify debris-covered ice}

477 SAR Coherence data requires expertise knowledge and expensive software in order to be processed

478 (Frey et al., 2012). Therefore, it was attempted to classify debris-covered ice based on optical and topographic data alone, especially since the data used for this (Landsat 8 and the SRTM DEM) are both freely available. When the SAR coherence data is excluded from the OBIA, the accuracy of the classification falls by $12.2 \%$. The spectrally based classification was sufficient on several of the larger debris-covered glaciers, where prominent shifts in lithology or vegetation represented the shift from debris-covered ice to stagnant ice, moraine or rock. In some cases however, the termini of glaciers were overestimated, with avalanche and debris flow deposits (Figure 9) as well as surface water leading to misclassifications of debris-covered ice. In many cases the delineations of debris-covered ice from the spectral classification varied by $30 \%$ or more when compared to the manually corrected outlines as a result of similar spectral signatures of the glacier debris and surrounding bedrock. The SAR coherence data also permits the distinction between active ice and stagnant ice when combined with optical and topographic data, something stated as a weakness in methods that only use optical and topographic data (Bolch et al., 2007, Ghosh et al., 2014). Although SAR coherence data has not been used within OBIA to map debris-covered ice, it has been used without additional data to automatically map ice in Alaska (Atwood et al., 2010), in combination with optical data for manual delineations (Frey et al., 2012). Zongli et al. (2011) used SAR coherence data within a Maximum Likelihood classification in China and pointed out problems of surface water also having low coherence values. Huang et al. (2014) used both a backscatter coefficient threshold (89.16\% accuracy) and multi-polarimetric analysis within a support-vector-machine (SVM) learning strategy. The latter achieved accuracies of $98.29 \%$ although the method is more complicated and was applied on only 1 glacier $\left(83.6 \mathrm{~km}^{2}\right)$. 
portions of the debris-covered tongues are often indistinguishable from stagnant ice and surrounding bedrock without SAR coherence data.

It is important to note that despite the improvement that the coherence data brings to the overall classification, it is not possible to classify debris-covered ice based solely on SAR coherence data as was done in Alaska by Atwood et al. (2010). This is because greater amounts of vegetation, steeper topography with unstable slopes and inactive debris-covered ice, all of which contribute to a loss of SAR coherence, are more widespread in the Himalayas than in Alaska (Frey et al., 2012). Optical data can be used to exclude glacial lakes, vegetation growing in the proximity of the glacier or on stagnant ice, while slope data can exclude steep gullies and paraglacial slopes. There are some areas, however, where SAR data was not received at the sensor due to the effects of steep topography on the radar image, namely layover and shadow, as well as problems in orthorectification in the absence of a high quality DEM. In areas where no SAR coherence data was returned, the classification relied solely on optical and topographic data, an additional advantage of using multiple data sources with OBIA. Use of SAR data acquired by a descending orbit would reduce the areas of missing information, but the ALOS operation strategy was to operate the SAR sensor only at night and therefore along ascending orbits. Other SAR sensors with short repeat intervals and high spatial resolution, such as TerraSAR-X and Sentinel-1, could be also considered for future studies.

\subsection{Importance of image segmentation and classification parameters}

Two of the most critical steps in the classification were the weights assigned to the input data, and the parameters used in the image segmentation. Assigning weights of importance for image classification of the coherence data, optical data and topographic data had to be selected carefully in order to exploit each dataset fully. Assigning a higher weight to the optical data could cause a reliance on the lithological composition of the debris cover at the expense of the SAR coherence or topographic data, while weighing the topographic data higher could cause problems when the newer, optical data conflicted with the topographic data. The end result varied considerably 
depending on the chosen weighting factors, and much time was spent trying to balance the data weight assignments as well as possible.

Care is required to decide which parameter sets (such as slope or NDVI) should be used in the classification. The Himalayas are a very heterogeneous region, thus one parameter threshold one area may not be in another. As few parameters as possible were chosen in order to make the classification more transferable between the different conditions in the Manaslu region. The parameters were limited to a few initial band ratios and indices before the delineations were expanded using contextual and relational properties.

Three segmentations were used in this study; a higher weighting factor on the slope helped to create larger objects over the gently sloping debris-covered glacier tongues, and smaller objects over the surrounding bedrock. This however caused some of the steeper glacier tributaries to be fragmented between objects, making it more difficult to include them in the classification. In particular some elongated features such as narrow nunataks were too small to be adequately depicted by segmentation and were therefore misclassified as clean ice. The classification procedure was made simpler by using multiple hierarchical segmentations to build large yet homogenous objects while minimising objects that included multiple classes. This made the subsequent classification procedure simpler.

\subsection{Use of topographic parameters for classifying debris-covered ice}

Several studies pointed to the importance of topographic parameters in the classification. Rastner et al. (2014) and Bajracharya et al. (2014a) both used the slope within OBIA to separate debris-covered ice and the surrounding valley sides, while the slope and curvature have been used in other methods such as cluster analysis or supervised classifications to map debris-covered ice based on its morphology (Paul et al., 2004, Ranzi et al., 2004, Bolch et al., 2007, Bhambri et al., 2011, Racoviteanu and Williams, 2012, Bhardwaj et al., 2014b, Tiwari et al., 2014). The slope was especially useful in separating debris-covered ice from the surrounding bedrock, whilst the elevation was used in 
separating glacial lakes from clean ice, and eliminating spectrally similar objects such as scree slopes that were found in lower valleys. There is a large potential to gain information by using the surface curvature and the surface roughness to demarcate the debris-covered portion of the glacier, as has been done in other studies (Paul et al., 2004, Bolch et al., 2007, Shukla et al., 2010, Bhambri et al., 2011, Bhardwaj et al., 2014b). Such information has not been included as part of an object-based classification of glacier ice before, and in particular could be useful for including the steep glacier tributaries that were missed from the classification. Edge detection of a break in slope or curvature could be used in creating image objects depicting the debris-covered glacier tongue. In this study the resolution of the SRTM DEM was not sufficient to use either the curvature or the surface roughness; however the future release of higher resolution DEMs such as the TanDEM-X Global DEM could increase the ability of an automated OBIA classification.

\section{$\underline{5.5 \text { Comparison between OBIA and pixel based methods }}$}

The use of OBIA has many advantages over standard pixel based methods. The ability to include contextual information permits the removal and subsequent reclassification of cloud and shadows that are surrounded by glacier ice. This reduces the amount of manual correction that is necessary. OBIA also allows glaciers to be efficiently broken down into their components (for example, clean ice, debris-covered ice and glacial lakes), while the ability to assign classes within a hierarchy allows suband supraclasses. This allows a "glacier" to be made up of "clean ice" and "debris-covered ice", or "glacial lakes" to be made up of "pro-glacial lakes", "supra-glacial lakes" and "marginal-glacier lakes". Hierarchical ordering of classifications also enables temporary classifications that can be used to expand classifications into troublesome areas.

Additionally, as OBIA permits the handling of optical, SAR and DEM data simultaneously, classifications can use a combination of remotely sensed data in order to determine a class, allowing an improvement of the classification of debris-covered ice when compared to pixel based methods. 
575 It should be noted though that pixel based methods are simpler to perform than OBIA, both in terms

576 of steps and technical knowledge needed when classifying, as well as computational power.

577 Nonetheless, OBIA can be recommended for future work on glacier inventories and glacier areas

578 estimations, but more so with either debris-covered ice or when working on very large areas in order

579 to reduce the amount of manual correction necessary.

\subsection{Future Directions}

581 Future studies should also explore using the NIR or Red spectral channels to separate clean ice from

582 snow-covered ice, thereby mapping the transient snow line (TSL). The highest altitude of the TSL

583 during an ablation season can be considered a proxy for the equilibrium line altitude (ELA) of a

584 glacier (Racoviteanu et al., 2008, Bishop et al., 2014).

585 Kääb et al. (2014) highlight the potential of comparing digital elevation models to map debris-

586 covered ice, given that any active ice has most likely experienced a change in surface elevation it

587 should be identifiable from the rate of elevation change. Such an approach requires less expertise

588 and pre-processing than calculating SAR coherence, and thus could be worthwhile to classify debris-

589 covered ice by including a change in elevation within OBIA.

590 The disparity found between the various glacier outlines compared in this study highlight the need

591 for frequent, up to date glacier inventories. Large differences were found for the glaciers north of the

592 mountain divide as a result of the 40 year difference between the creation of the two inventories.

593 Remote sensing and GIS technologies, such as OBIA, facilitate the automatic or semi-automatic

594 creation of regular glacier inventories, however differences in arbitrary thresholds such as the upper

595 elevation and upper slope threshold cause significant differences in the upper boundaries of glaciers.

596 This study used shallower slope thresholds than the ICIMOD inventory in order to exclude false

597 positives; thresholds selected depend on the specific datasets used and also vary by location.

598 Nonetheless, if multiple glacier inventories are used to assess areal changes over time, problems can 
arise. For example, there is no clear consensus on the upper bounds of the accumulation area, nor whether steep terrain that contributes snow and ice to the glacier through avalanching should be considered as a part of the glacier. It is interesting that some changes between the reference glacier inventory and the outlines derived in this study were due to differences in these upper delineations, and could cause noise when assessing glacier area change between multiple inventories. Through initiatives such as GLIMS and the Randolph Glacier Inventory, a defined outline for the use of OBIA could be used to streamline the creation and maintenance of glacier outlines.

\section{Conclusions}

Remote sensing glaciology, and in particular large scale glacier mapping is hampered by glacier debris being spectrally indistinguishable from the surrounding terrain. This study has shown that OBIA can be used effectively for automated mapping of glaciers; both clean ice and debris-covered ice, and has many advantages over traditional pixel-based methods. OBIA permits the handling of multiple data types including optical, SAR and elevation data, while hierarchical and contextual capabilities allow rule sets such as excluding debris-covered ice not adjacent to clean ice, including neighbouring objects that are spectrally similar or determining an object's class by its shape or area. These capabilities of OBIA also reduce the amount of post-processing that is needed while enhancing the potential to enhance glacier mapping to the various types of glacier surfaces (i.e. snow lines, debriscover type, lake detection etc...)

We have shown that by combining SAR coherence data with optical satellite imagery and topographic data in an OBIA, it is possible to accurately map clean ice and debris-covered ice, even with course-resolution elevation data, such as the 90 metre SRTM DEM.

This OBIA however has some restrictions when it comes to steep, unstable valley slopes, rock slides, flowing surface water, and vegetation. In addition, the mountainous terrain in our study area results in SAR data not always being retrievable due to shadowing and layover effects. Nevertheless, over a large $\left(788 \mathrm{~km}^{2}\right)$ study area we semi-automatically mapped the clean ice with an accuracy of $93.3 \%$ 

over the entire glacier of $91.1 \%$. This accuracy can be improved using a higher resolution DEM, and/or by using temporally consistent data within the classification, while if steep, tributary sections of ice can be contextually included then the accuracy will rise to over $94 \%$.

Based on our results we can recommend the use of OBIA incorporating SAR coherence data with optical imagery and topographic data within OBIA for future studies mapping heavily debris-covered glaciated regions at a large spatial scale.

\section{Acknowledgments}

First and foremost the authors would like to thank Asha Badadur Rai (www.adventurousnepal.com) and his family for organising all the logistics and practicalities of our fieldwork trekking around the Manaslu Conservation Area in both 2013 and 2014 and making us very welcome in Nepal. Thanks also to Tommy Robson and Ingrid Lycke Austb $\varnothing$ for proof reading this manuscript. Thanks to the three reviewers who had many helpful comments and suggestions and vastly improved the quality of this paper. We are also very grateful to both ResClim and Meltzer for the additional funding received for this project. Christopher Nuth acknowledges support by the European Research Council under the

320816. This study is also a contribution from the ESA project Glaciers_cci (4000109873/14/I-NB) the USGS for free provision of Landsat 8 and SRTM data. Daniel Hölbling has been partly supported Type Glacier in the Nepal Himalaya. Geografiska Annaler Series a-Physical Geography, 66, 249-255.

Albert, T. H. 2002. Evaluation of Remote Sensing Techniques for Ice-Area Classification Applied to the Tropical Quelccaya Ice Cap, Peru. Polar Geography, 26, 210-226.

Alifu, H., Tateishi, R. \& Johnson, B. 2015. A new band ratio technique for mapping debris-covered glaciers using Landsat imagery and a digital elevation model. International Journal of Remote Sensing, 36, 2063-2075. 
Arendt, A., Bolch, T., Cogley, J. G., Gardner, A., Hagen, J.-O., Hock, R., Kaser, G., Pfeffer, W. T., Moholdt, G., Paul, F., et al. 2012. Randolph Glacier Inventory - A Dataset of Global Glacier Outlines: Version 3.2. Global Land Ice Measurements from Space: Boulder Colorado, USA.

Atwood, D. K., Meyer, F. \& Arendt, A. 2010. Using L-band SAR coherence to delineate glacier extent. Canadian Journal of Remote Sensing, 36, S186-S195.

Bajracharya, S. \& Shrestha, B. 2011. The status of glaciers in the Hindu Kush-Himalayan region. Kathmandu: ICIMOD.

Bajracharya, S. R., Maharjan, S. B. \& Shrestha, F. 2014a. The status and decadal change of glaciers in Bhutan from the 1980's to 2010 based on satellite data.'. Annals of Glaciology, 55, 159-166.

Bajracharya, S. R., Maharjan, S. B., Shrestha, F., Bajracharya, O. R. \& Baidya, S. 2014b. Glacier Status in Nepal and Decadal Change from 1980 to 2010 Based on Landsat Data. Kathmandu: ICIMOD.

Bajracharya, S. R., Maharjan, S. B., Shrestha, F., Guo, W., Liu, S., Immerzeel, W. \& Shrestha, B. 2015. The glaciers of the Hindu Kush Himalayas: current status and observed changes from the 1980s to 2010. International Journal of Water Resources Development, 31, 161-173.

Benn, D. I., Bolch, T., Hands, K., Gulley, J., Luckman, A., Nicholson, L. I., Quincey, D., Thompson, S., Toumi, R. \& Wiseman, S. 2012. Response of debris-covered glaciers in the Mount Everest region to recent warming, and implications for outburst flood hazards. Earth-Science Reviews, 114, 156-174.

Benn, D. I. \& Evans, D. J. 2010. Glaciers and glaciation, Hodder Education.

Benn, D. I. \& Owen, L. A. 1998. The role of the Indian summer monsoon and the mid-latitude westerlies in Himalayan glaciation: review and speculative discussion. Journal of the Geological Society, 155, 353-363.

Benz, U. C., Hofmann, P., Willhauck, G., Lingenfelder, I. \& Heynen, M. 2004. Multi-resolution, objectoriented fuzzy analysis of remote sensing data for GIS-ready information. Isprs Journal of Photogrammetry and Remote Sensing, 58, 239-258.

Berthier, E., Arnaud, Y., Kumar, R., Ahmad, S., Wagnon, P. \& Chevallier, P. 2007. Remote sensing estimates of glacier mass balances in the Himachal Pradesh (Western Himalaya, India). Remote Sensing of Environment, 108, 327-338.

Berthier, E., Schiefer, E., Clarke, G. K. C., Menounos, B. \& Remy, F. 2010. Contribution of Alaskan glaciers to sea-level rise derived from satellite imagery. Nature Geoscience, 3, 92-95.

Berthier, E., Vadon, H., Baratoux, D., Arnaud, Y., Vincent, C., Feigl, K. L., Remy, F. \& Legresy, B. 2005. Surface motion of mountain glaciers derived from satellite optical imagery. Remote Sensing of Environment, 95, 14-28.

Bhambri, R., Bolch, T. \& Chaujar, R. K. 2011. Mapping of debris-covered glaciers in the Garhwal Himalayas using ASTER DEMs and thermal data. International Journal of Remote Sensing, 32, 8095-8119.

Bhardwaj, A., Joshi, P. K., Snehmani, Singh, M. K., Sam, L. \& Gupta, R. D. 2014a. Mapping debriscovered glaciers and identifying factors affecting the accuracy. Cold Regions Science and Technology, 106, 161-174.

Bhardwaj, A., Joshi, P. K., Snehmani, Singh, M. K., Sam, L. \& Gupta, R. D. 2014b. Mapping debriscovered glaciers and identifying factors affecting the accuracy. Cold Regions Science and Technology, 106-107, 161-174.

Bishop, M., Bush, A. G., Furfaro, R., Gillespie, A., Hall, D., Haritashya, U. \& Shroder, J., Jr. 2014. Theoretical Foundations of Remote Sensing for Glacier Assessment and Mapping. In: KARGEL, J. S., LEONARD, G. J., BISHOP, M. P., KÄÄB, A. \& RAUP, B. H. (eds.) Global Land Ice Measurements from Space. Springer Berlin Heidelberg.

Blaschke, T. 2010. Object based image analysis for remote sensing. Isprs Journal of Photogrammetry and Remote Sensing, 65, 2-16.

Blaschke, T., Hay, G. J., Kelly, M., Lang, S., Hofmann, P., Addink, E., Feitosa, R. Q., Van Der Meer, F., Van Der Werff, H., Van Coillie, F., et al. 2014. Geographic Object-Based Image Analysis - 
Towards a new paradigm. Isprs Journal of Photogrammetry and Remote Sensing, 87, 180191.

Blaschke, T. \& Strobl, J. 2001. What's wrong with pixels? Some recent developments interfacing remote sensing and GIS. GIS - Zeitschrift für Geoinformationssysteme, 6, 12-17.

Bolch, T., Buchroithner, M., Pieczonka, T. \& Kunert, A. 2008a. Planimetric and volumetric glacier changes in the Khumbu Himal, Nepal, since 1962 using Corona, Landsat TM and ASTER data. Journal of Glaciology, 54, 592-600.

Bolch, T., Buchroithner, M. F., Kunert, A. \& Kamp, U. Automated delineation of debris-covered glaciers based on ASTER data. Geoinformation in Europe (Proc. of 27th EARSel Symposium, 04-07 June 2007), Bozen, Italy, 2007. 403-410.

Bolch, T., Buchroithner, M. F., Peters, J., Baessler, M. \& Bajracharya, S. 2008b. Identification of glacier motion and potentially dangerous glacial lakes in the Mt. Everest region/Nepal using spaceborne imagery. Natural Hazards and Earth System Sciences, 8, 1329-1340.

Bolch, T., Kulkarni, A., Kaab, A., Huggel, C., Paul, F., Cogley, J. G., Frey, H., Kargel, J. S., Fujita, K., Scheel, M., et al. 2012. The State and Fate of Himalayan Glaciers. Science, 336, 310-314.

Brenning, A., Pena, M. A., Long, S. \& Soliman, A. 2012. Thermal remote sensing of ice-debris landforms using ASTER: an example from the Chilean Andes. Cryosphere, 6, 367-382.

Casey, K. A., Kaab, A. \& Benn, D. I. 2012. Geochemical characterization of supraglacial debris via in situ and optical remote sensing methods: a case study in Khumbu Himalaya, Nepal. Cryosphere, 6, 85-100.

Catani, F., Farina, P., Moretti, S., Nico, G. \& Strozzi, T. 2005. On the application of SAR interferometry to geomorphological studies: Estimation of landform attributes and mass movements. Geomorphology, 66, 119-131.

Cuffey, K. M. \& Paterson, W. S. B. 2010. The physics of glaciers, Academic Press.

De Ferranti, J. 2012. Viewfinder panoramas [Online]. Available: http://www.viewfinderpanoramas.org/ [Accessed 15/06/2013.

Drăguţ, L., Csillik, O., Eisank, C. \& Tiede, D. 2014. Automated parameterisation for multi-scale image segmentation on multiple layers. ISPRS Journal of Photogrammetry and Remote Sensing, 88, 119-127.

Frey, H., Paul, F. \& Strozzi, T. 2012. Compilation of a glacier inventory for the western Himalayas from satellite data: methods, challenges, and results. Remote Sensing of Environment, 124, 832843.

Gao, Y., Mas, J. F., Maathuis, B. H. P., Zhang, X. M. \& Van Dijk, P. M. 2006. Comparison of pixel-based and object-oriented image classification approaches - a case study in a coal fire area, Wuda, Inner Mongolia, China. International Journal of Remote Sensing, 27, 4039-4055.

Gardelle, J., Berthier, E., Arnaud, Y. \& Kääb, A. 2013. Region-wide glacier mass balances over the Pamir-Karakoram-Himalaya during 1999 - 2011. The Cryosphere, 7, 1263-1286.

Ghosh, S., Pandey, A. C. \& Nathawat, M. S. 2014. Mapping of debris-covered glaciers in parts of the Greater Himalaya Range, Ladakh, western Himalaya, using remote sensing and GIS. Journal of Applied Remote Sensing, 8, 083579-083579.

Glims 2014. GLIMS Glacier Database [South Asia]. In: NATIONAL SNOW AND ICE DATA CENTRE (ed.). Boulder, Colorado, USA.

Government of Nepal, D. O. H. a. M. 2014. Interpolated $12 \mathrm{~km}$ Temperature and Rainfall Mean Annual Data (1970 - 2010) [Online]. Kathmandu, Nepal. Available: http://dhm.gov.np/dpc.

Hoersch, B. \& Amans, V. 2012. GMES space component data access portfolio: data warehouse 20112014. Frascati, Italy: European Space Agency.

Huang, L., Li, Z., Tian, B. S., Zhou, J. M. \& Chen, Q. 2014. Recognition of supraglacial debris in the Tianshan Mountains on polarimetric SAR images. Remote Sensing of Environment, 145, 4754.

Hölbling, D., Friedl, B. \& Eisank, C. 2015. An object-based approach for semi-automated landslide change detection and attribution of changes to landslide classes in northern Taiwan. Earth Science Informatics, 1-9. 
Icimod 2010. Glacier Mapping and Monitoring Tools and techniques. In: BAJRACHARYA, S. R. \& MOOL, P. (eds.). ICIMOD.

Immerzeel, W. W., Kraaijenbrink, P. D. A., Shea, J. M., Shrestha, A. B., Pellicciotti, F., Bierkens, M. F. P. \& De Jong, S. M. 2014. High-resolution monitoring of Himalayan glacier dynamics using unmanned aerial vehicles. Remote Sensing of Environment, 150, 93-103.

Immerzeel, W. W., Van Beek, L. P. H. \& Bierkens, M. F. P. 2010. Climate Change Will Affect the Asian Water Towers. Science, 328, 1382-1385.

Joyce, K. E., Samsonov, S. V., Levick, S. R., Engelbrecht, J. \& Belliss, S. 2014. Mapping and monitoring geological hazards using optical, LiDAR, and synthetic aperture RADAR image data. Natural Hazards, 73, 137-163.

Juen, M., Mayer, C., Lambrecht, A., Han, H. \& Liu, S. 2014. Impact of varying debris cover thickness on ablation: a case study for Koxkar Glacier in the Tien Shan. Cryosphere, 8, 377-386.

Karimi, N., Farokhnia, A., Shishangosht, S., Elmi, M., Eftekhari, M. \& Ghalkhani, H. 2012. Elevation changes of Alamkouh glacier in Iran since 1955, based on remote sensing data. International Journal of Applied Earth Observation and Geoinformation, 19, 45-58.

Keshri, A. K., Shukla, A. \& Gupta, R. P. 2009. ASTER ratio indices for supraglacial terrain mapping. International Journal of Remote Sensing, 30, 519-524.

Kääb, A. 2005. Combination of SRTM3 and repeat ASTER data for deriving alpine glacier flow velocities in the Bhutan Himalaya. Remote Sensing of Environment, 94, 463-474.

Kääb, A., Bolch, T., Casey, K., Heid, T., Kargel, J., Leonard, G., Paul, F. \& Raup, B. 2014. Glacier Mapping and Monitoring Using Multispectral Data. In: KARGEL, J. S., LEONARD, G. J., BISHOP, M. P., KÄÄB, A. \& RAUP, B. H. (eds.) Global Land Ice Measurements from Space. Springer Berlin Heidelberg.

Lang, S. 2008. Object-based image analysis for remote sensing applications: modeling reality dealing with complexity. In: BLASCHKE, T., LANG, S. \& HAY, G. (eds.) Object-Based Image Analysis. Springer Berlin Heidelberg.

Mool, P., Maskey, P. R., Koirala, A., Joshi, S. P., Lizong, W., Shrestha, A. B., Eriksson, M., Gurung, B., Pokharel, B., Khanal, N. R., et al. 2011. Glacial Lakes and Glacial Lake Outburst Floods in Nepal. Kathmandu: ICIMOD.

Moosavi, V., Talebi, A. \& Shirmohammadi, B. 2014. Producing a landslide inventory map using pixelbased and object-oriented approaches optimized by Taguchi method. Geomorphology, 204, 646-656.

Myint, S. W., Gober, P., Brazel, A., Grossman-Clarke, S. \& Weng, Q. H. 2011. Per-pixel vs. objectbased classification of urban land cover extraction using high spatial resolution imagery. Remote Sensing of Environment, 115, 1145-1161.

Nuimura, T., Sakai, A., Taniguchi, K., Nagai, H., Lamsal, D., Tsutaki, S., Kozawa, A., Hoshina, Y., Takenaka, S., Omiya, S., et al. 2014. The GAMDAM Glacier Inventory: a quality controlled inventory of Asian glaciers. The Cryosphere Discuss., 8, 2799-2829.

Nuth, C., Kohler, J., König, M., Von Deschwanden, A., Hagen, J. O., Kääb, A., Moholdt, G. \& Pettersson, R. 2013. Decadal changes from a multi-temporal glacier inventory of Svalbard. The Cryosphere, 7, 1603-1621.

Owen, L. A. \& Benn, D. I. 2005. Equilibrium-line altitudes of the Last Glacial Maximum for the Himalaya and Tibet: an assessment and evaluation of results. Quaternary International, 138139, 55-78.

Paul, F. \& Andreassen, L. M. 2009. A new glacier inventory for the Svartisen region, Norway, from Landsat ETM+ data: challenges and change assessment. Journal of Glaciology, 55, 607-618.

Paul, F., Barrand, N., Baumann, S., Berthier, E., Bolch, T., Casey, K., Frey, H., Joshi, S., Konovalov, V. \& Bris, R. L. 2013a. On the accuracy of glacier outlines derived from remote-sensing data. Annals of Glaciology, 54, 171-182.

Paul, F., Bolch, T., Kääb, A., Nagler, T., Nuth, C., Scharrer, K., Shepherd, A., Strozzi, T., Ticconi, F. \& Bhambri, R. 2013b. The glaciers climate change initiative: Methods for creating glacier area, elevation change and velocity products. Remote Sensing of Environment. 
Paul, F., Bolch, T., Kääb, A., Nagler, T., Nuth, C., Scharrer, K., Shepherd, A., Strozzi, T., Ticconi, F., Bhambri, R., et al. 2013c. The glaciers climate change initiative: Methods for creating glacier area, elevation change and velocity products. Remote Sensing of Environment, 162, 408-426.

Paul, F., Huggel, C. \& Kaab, A. 2004. Combining satellite multispectral image data and a digital elevation model for mapping debris-covered glaciers. Remote Sensing of Environment, 89, 510-518.

Pfeffer, W. T., Arendt, A. A., Bliss, A., Bolch, T., Cogley, J. G., Gardner, A. S., Hagen, J. O., Hock, R., Kaser, G., Kienholz, C., et al. 2014. The Randolph Glacier Inventory: a globally complete inventory of glaciers. Journal of Glaciology, 60, 537-552.

Pradhananga, N. S., Kayastha, R. B., Bhattarai, B. C., Adhikari, T. R., Pradhan, S. C., Devkota, L. P., Shrestha, A. B. \& Mool, P. K. 2014. Estimation of discharge from Langtang River basin, Rasuwa, Nepal, using a glacio-hydrological model. Annals of Glaciology, 55, 223-230.

Pratap, B., Dobhal, D., Mehta, M. \& Bhambri, R. 2015. Influence of debris cover and altitude on glacier surface melting: a case study on Dokriani Glacier, central Himalaya, India. Annals of Glaciology, 56, 9.

Quincey, D. J., Luckman, A. \& Benn, D. 2009. Quantification of Everest region glacier velocities between 1992 and 2002, using satellite radar interferometry and feature tracking. Journal of Glaciology, 55, 596-606.

Racoviteanu, A. \& Williams, M. W. 2012. Decision Tree and Texture Analysis for Mapping DebrisCovered Glaciers in the Kangchenjunga Area, Eastern Himalaya. Remote Sensing, 4, 30783109.

Racoviteanu, A. E., Armstrong, R. \& Williams, M. W. 2013. Evaluation of an ice ablation model to estimate the contribution of melting glacier ice to annual discharge in the Nepal Himalaya. Water Resources Research, 49, 5117-5133.

Racoviteanu, A. E., Paul, F., Raup, B., Khalsa, S. J. S. \& Armstrong, R. 2009. Challenges and recommendations in mapping of glacier parameters from space: results of the $2008 \mathrm{Global}$ Land Ice Measurements from Space (GLIMS) workshop, Boulder, Colorado, USA. Annals of Glaciology, 50, 53-69.

Racoviteanu, A. E., Williams, M. W. \& Barry, R. G. 2008. Optical remote sensing of glacier characteristics: A review with focus on the Himalaya. Sensors, 8, 3355-3383.

Ranzi, R., Grossi, G., lacovelli, L. \& Taschner, S. 2004. Use of multispectral ASTER images for mapping debris-covered glaciers within the GLIMS Project. Igarss 2004: leee International Geoscience and Remote Sensing Symposium Proceedings, Vols 1-7, 1144-1147.

Rastner, P., Bolch, T., Notarnicola, C. \& Paul, F. 2014. A Comparison of Pixel- and Object-Based Glacier Classification With Optical Satellite Images. leee Journal of Selected Topics in Applied Earth Observations and Remote Sensing, 7, 853-862.

Rees, H. G. \& Collins, D. N. 2006. Regional differences in response of flow in glacier-fed Himalayan rivers to climatic warming. Hydrological Processes, 20, 2157-2169.

Rexer, M. \& Hirt, C. 2014. Comparison of free high resolution digital elevation data sets (ASTER GDEM2, SRTM v2.1/v4.1) and validation against accurate heights from the Australian National Gravity Database. Australian Journal of Earth Sciences, 61, 213-226.

Reznichenko, N., Davies, T., Shulmeister, J. \& Mcsaveney, M. 2010. Effects of debris on ice-surface melting rates: an experimental study. Journal of Glaciology, 56, 384-394.

Richardson, S. D. \& Reynolds, J. M. 2000. An overview of glacial hazards in the Himalayas. Quaternary International, 65-6, 31-47.

Saraswat, P., Syed, T. H., Famiglietti, J. S., Fielding, E. J., Crippen, R. \& Gupta, N. 2013. Recent changes in the snout position and surface velocity of Gangotri glacier observed from space. International Journal of Remote Sensing, 34, 8653-8668.

Scherler, D., Bookhagen, B. \& Strecker, M. R. 2011. Spatially variable response of Himalayan glaciers to climate change affected by debris cover. Nature Geoscience, 4, 156-159. 
Shangguan, D., Liu, S., Ding, Y., Wu, L., Deng, W., Guo, W., Wang, Y., Xu, J., Yao, X. \& Guo, Z. 2014. Glacier changes in the Koshi River basin, central Himalaya, from 1976 to 2009, derived from remote-sensing imagery. Annals of Glaciology, 55, 61.

Sharma, A. K., Singh, S. K., Kulkarni, A. V. \& Ajai 2013. Glacier Inventory in Indus, Ganga and Brahmaputra Basins of the Himalaya. National Academy Science Letters-India, 36, 497-505.

Shukla, A., Arora, M. \& Gupta, R. 2010. Synergistic approach for mapping debris-covered glaciers using optical-thermal remote sensing data with inputs from geomorphometric parameters. Remote Sensing of Environment, 114, 1378-1387.

Snehmani, Singh, M. K., Gupta, R., Bhardwaj, A. \& Joshi, P. K. 2014. Remote sensing of mountain snow using active microwave sensors: a review. Geocarto International, 1-27.

Strozzi, T., Dammert, P. B. G., Wegmuller, U., Martinez, J. M., Askne, J. I. H., Beaudoin, A. \& Hallikainen, M. T. 2000. Landuse mapping with ERS SAR interferometry. leee Transactions on Geoscience and Remote Sensing, 38, 766-775.

Tachikawa, T., Kaku, M., Iwasaki, A., Gegch, D., Oimoen, M., Zhang, Z., Danielson, J., Krieger, T., Curtis, B., Haase, J., et al. 2011. ASTER Global Digital Elevation Model Version 2 - Summary of Validation Results. In: MEYER, D. (ed.). Earth Remote Sensing Data Analysis Center (ERSDAC).

Takeuchi, Y., Kayastha, R. B. \& Nakawo, M. 2000. Characteristics of ablation and heat balance in debris-free and debris-covered areas on Khumbu Glacier, Nepal Himalayas, in the premonsoon season. IAHS PUBLICATION, 53-62.

Tiwari, R. K., Arora, M. K. \& Gupta, R. P. 2014. Comparison of maximum likelihood and knowledgebased classifications of debris cover of glaciers using aster optical-thermal imagery. Remote Sensing of Environment.

Townshend, J., Huang, C., Kalluri, S., Defries, R., Liang, S. \& Yang, K. 2000. Beware of per-pixel characterization of land cover. International Journal of remote sensing, 21, 839-843.

Zhang, Y., Fujita, K., Liu, S. Y., Liu, Q. \& Nuimura, T. 2011. Distribution of debris thickness and its effect on ice melt at Hailuogou glacier, southeastern Tibetan Plateau, using in situ surveys and ASTER imagery. Journal of Glaciology, 57, 1147-1157.

Zongli, J., Shiyin, L., Xin, W., Jian, L. \& Sichun, L. Applying SAR interferometric coherence to outline debris-covered glacier. Geoinformatics, 2011 19th International Conference on, 24-26 June 2011 2011. 1-4. 
Table A1: Comparison of glacier areas of both clean and debris-covered ice, as derived from the 2010 ICIMOD Glacier Inventory, manual delineation, a spectrally based OBIA and a SAR based OBIA.

889

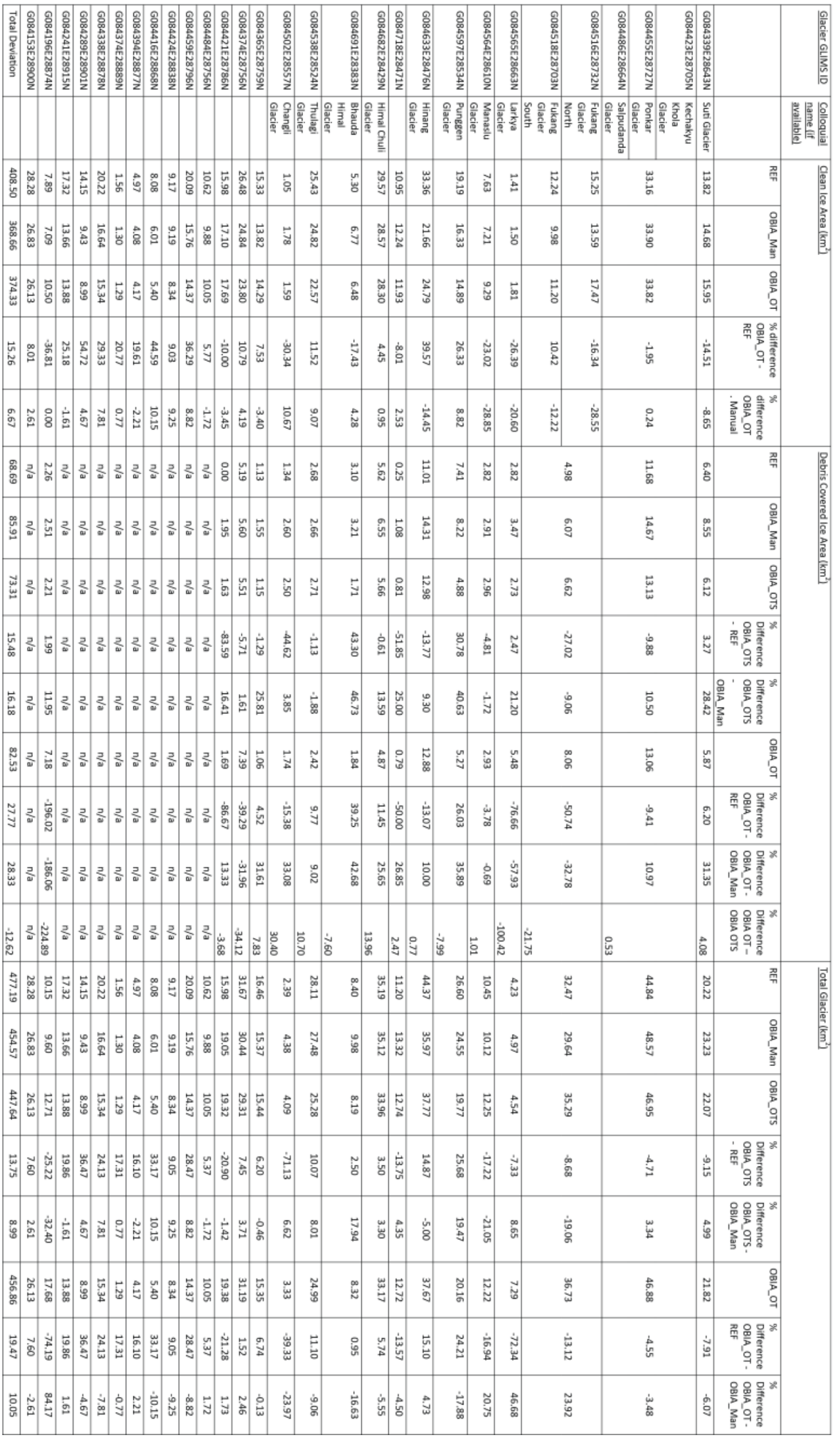


Table A2: Comparison between the manually delineated outline and the OBIA_OTS classifications when steep tributaries of the glaciers are excluded

\begin{tabular}{|c|c|c|c|c|c|c|c|c|c|c|}
\hline & \multicolumn{5}{|c|}{ Debris Covered Ice (clipped) $\left(\mathrm{km}^{2}\right)$} & \multicolumn{5}{|c|}{ Total Glacier (clipped) $\left(\mathrm{km}^{2}\right)$} \\
\hline GLIMS Glacier ID & OBIA_Man & OBIA_OTS & $\begin{array}{c}\% \\
\text { Difference } \\
\text { OBIA_OTS } \\
- \\
\text { OBIA_Man }\end{array}$ & OBIA_OT & $\begin{array}{c}\% \\
\text { Difference } \\
\text { OBIA_OT - } \\
\text { OBIA_Man }\end{array}$ & OBIA_Man & OBIA_OTS & $\begin{array}{c}\% \\
\text { Difference } \\
\text { OBIA_OTS } \\
- \\
\text { OBIA_Man }\end{array}$ & OBIA_OT & $\begin{array}{c}\% \\
\text { Difference } \\
\text { OBIA_OT - } \\
\text { OBIA_Man }\end{array}$ \\
\hline G084339E28643N & 6.21 & 6.12 & 1.46 & 5.87 & 5.44 & 20.89 & 22.07 & -5.65 & 21.82 & -4.46 \\
\hline G084423E28705N & \multirow{3}{*}{12.55} & \multirow{3}{*}{13.13} & \multirow{3}{*}{-4.64} & \multirow{3}{*}{13.06} & \multirow{3}{*}{-4.10} & \multirow{3}{*}{46.45} & \multirow{3}{*}{46.95} & \multirow{3}{*}{-1.08} & \multirow{3}{*}{46.88} & \multirow{3}{*}{-0.93} \\
\hline G084455E28727N & & & & & & & & & & \\
\hline G084486E28664N & & & & & & & & & & \\
\hline G084516E28732N & \multirow{2}{*}{5.80} & \multirow{2}{*}{6.62} & \multirow{2}{*}{-14.05} & \multirow{2}{*}{8.06} & \multirow{2}{*}{-38.89} & \multirow[t]{2}{*}{19.39} & \multirow{2}{*}{24.09} & \multirow{2}{*}{-24.21} & \multirow{2}{*}{25.53} & \multirow{2}{*}{-31.64} \\
\hline G084518E28703N & & & & & & & & & & \\
\hline G084565E28663N & 2.60 & 2.70 & -3.94 & 5.48 & -111.13 & 4.10 & 4.51 & -10.06 & 7.29 & -78.01 \\
\hline G084564E28610N & 2.82 & 2.96 & -5.03 & 2.93 & -3.95 & 10.03 & 12.25 & -22.15 & 12.22 & -21.85 \\
\hline G084597E28534N & 4.24 & 4.88 & -15.05 & 5.27 & -24.27 & 20.57 & 19.77 & 3.90 & 20.16 & 2.00 \\
\hline G084633E28476N & 11.50 & 12.98 & -12.92 & 12.88 & -12.02 & 33.16 & 37.77 & -13.92 & 37.67 & -13.61 \\
\hline G084718E28471N & 0.98 & 0.81 & 17.53 & 0.79 & 19.37 & 13.22 & 12.74 & 3.64 & 12.72 & 3.78 \\
\hline G084682E28429N & 5.77 & 5.66 & 1.88 & 4.87 & 15.58 & 34.34 & 33.96 & 1.10 & 33.17 & 3.40 \\
\hline G084691E28383N & 1.64 & 1.71 & -4.43 & 1.84 & -12.01 & 8.41 & 8.19 & 2.58 & 8.32 & 1.11 \\
\hline G084538E28524N & 2.31 & 2.71 & -17.45 & 2.42 & -4.77 & 27.13 & 25.28 & 6.81 & 24.99 & 7.89 \\
\hline G084502E28557N & 1.68 & 2.50 & -48.96 & 1.74 & -3.37 & 3.46 & 4.09 & -18.28 & 3.33 & 3.86 \\
\hline G084365E28759N & 1.23 & 1.15 & 6.38 & 1.06 & 14.10 & 15.05 & 15.44 & -2.60 & 15.35 & -1.97 \\
\hline G084374E28756N & 5.04 & 5.51 & -9.29 & 7.39 & -46.70 & 29.88 & 29.31 & 1.91 & 31.19 & -4.40 \\
\hline G084421E28786N & 1.85 & 1.63 & 11.78 & 1.69 & 8.52 & 18.95 & 19.32 & -1.96 & 19.38 & -2.28 \\
\hline G084196E28874N & 2.14 & 2.21 & -3.29 & 7.18 & -235.54 & 12.02 & 12.26 & -2.00 & 17.23 & -43.35 \\
\hline Total & 68.36 & 73.29 & 9.17 & 82.53 & 25.89 & 327.03 & 339.21 & 5,98 & 348.45 & 8,90 \\
\hline
\end{tabular}


Table 1: Custom indices used in the glacier classifications.

\begin{tabular}{|l|l|l|}
\hline Index Acronym & Custom Index Name & Band Formula \\
\hline NDVI & $\begin{array}{l}\text { Normalized Difference } \\
\text { Vegetation Index }\end{array}$ & (NIR-Red)/(NIR + Red) \\
\hline NDSI & $\begin{array}{l}\text { Normalized Difference Snow } \\
\text { and Ice Index }\end{array}$ & (Green - (SWIR)/(Green + SWIR) \\
\hline NDWI & $\begin{array}{l}\text { Normalised Difference Water } \\
\text { Index }\end{array}$ & (Green - NIR)/(Green + NIR) \\
\hline LWM & Land and Water Mask & (SWIR/Green + 0.001) x 100 \\
\hline SWIR/NIR & $\begin{array}{l}\text { Commonly referred to as } \\
\text { TM4/TM5 }\end{array}$ & SWIR/NIR \\
\hline
\end{tabular}

901

902

903

Table 2: Data used in this study

\begin{tabular}{|l|l|l|l|}
\hline Date & Sensor & Scene ID & $\begin{array}{l}\text { Spatial Resolution } \\
(\mathrm{m})\end{array}$ \\
\hline 08.10.2013 & Landsat 8 & LC81420402013281LGN00 & 30 (15 pan-sharp) \\
\hline 26.12 .2013 & Landsat 8 & LC81420402013361LGN00 & 30 (15 pan-sharp) \\
\hline 20.11 .2012 & RapidEYE & 11240644 & 5 \\
\hline 11.02 .2000 & SRTM & SRTM3N28E084V2 & 90 \\
\hline 19.08 .2007 & ALOS PALSAR & $\begin{array}{l}\text { Coherence image from pair: } \\
\text { ALOS_511560560_20070704_20070819.cc }\end{array}$ & $\begin{array}{l}16 \mathrm{~m} \times 13 \mathrm{~m}, \\
\text { geocoded to 1 } \\
\text { arc-second ( 30 } \\
\text { meters) }\end{array}$ \\
\hline 05.09 .2007 & ALOS PALSAR & $\begin{array}{l}\text { Coherence image from pair: } \\
\text { ALOS_512560560_20070721_20070905.cc }\end{array}$ & $\begin{array}{l}16 \mathrm{~m} \times 13 \mathrm{~m}, \\
\text { geocoded to 1 } \\
\text { arc-second ( 30 } \\
\text { meters) }\end{array}$ \\
\hline
\end{tabular}



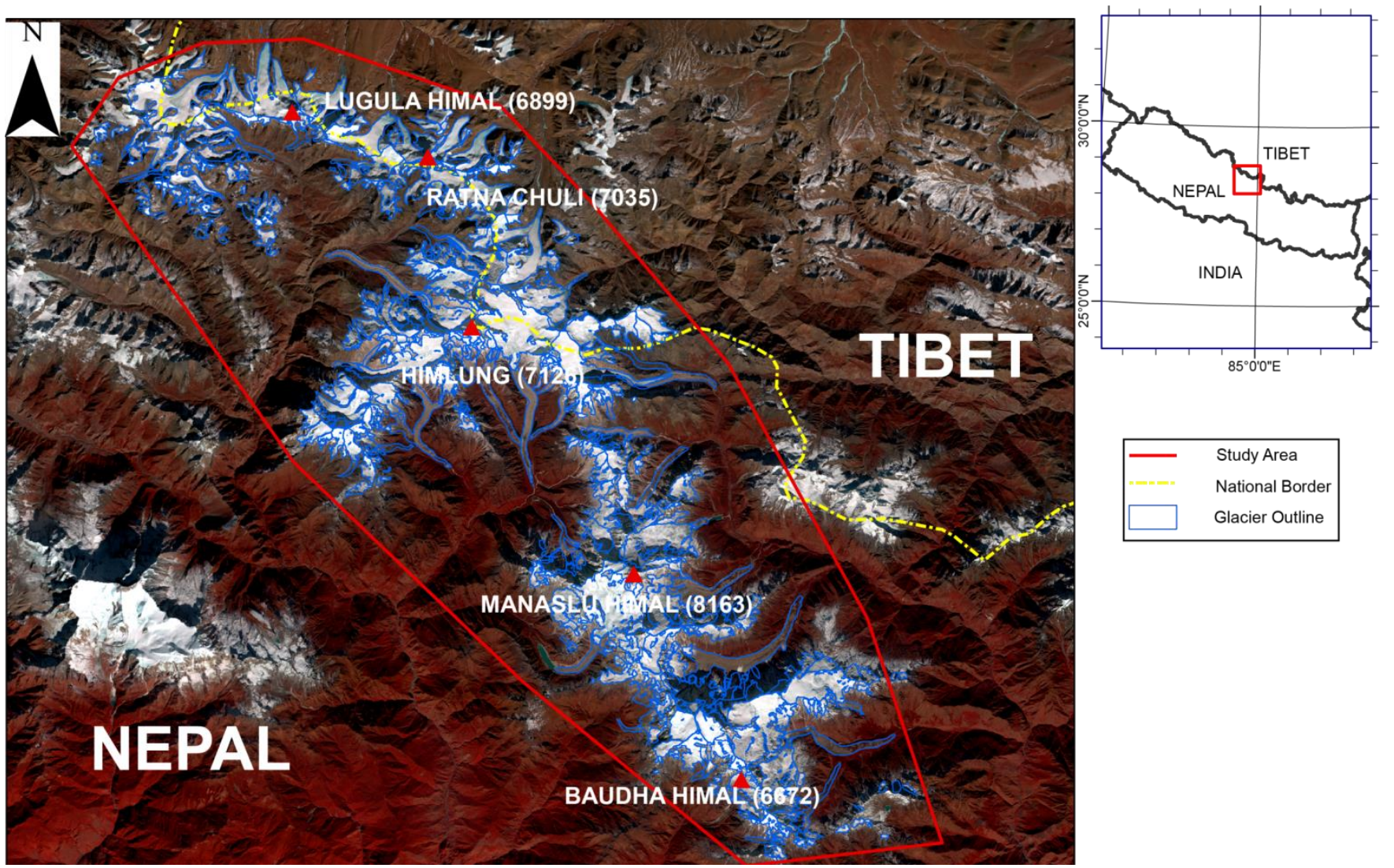

Figure 1: Location of the glaciers studied (outlines derived from this study) within the Manaslu Region $\left(28^{\circ} \mathrm{N}, 84^{\circ} \mathrm{E}\right)$, and the location of the Manaslu Region within Nepal. 


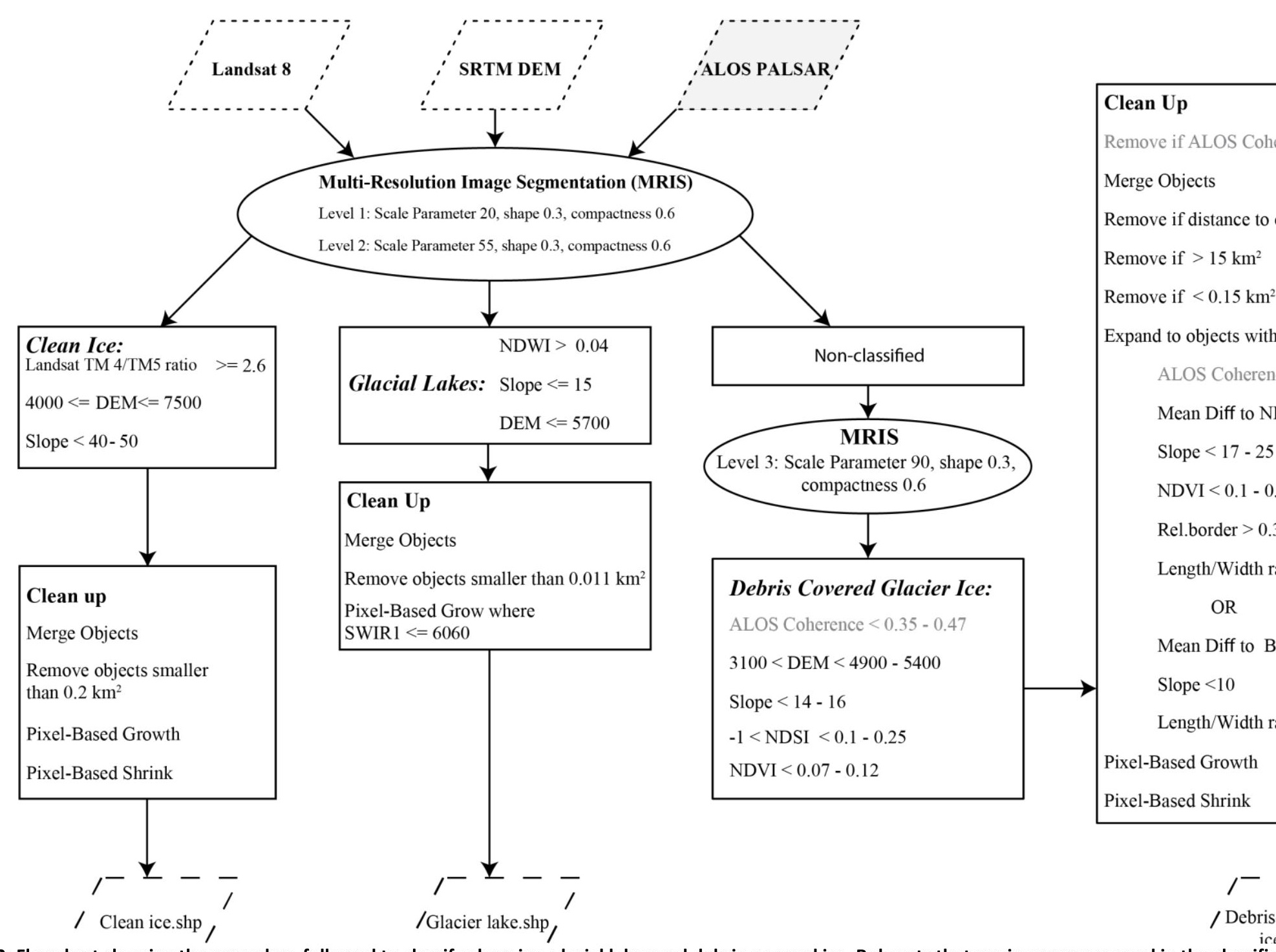

Figure 2: Flowchart showing the procedure followed to classify clean ice, glacial lakes and debris-covered ice. Rule sets that are in grey were used in the classific Coherence data in addition to Landsat 8 optical and SRTM elevation data, while the other classification relied solely on the optical and elevation data. An explai is given in 3.2. 


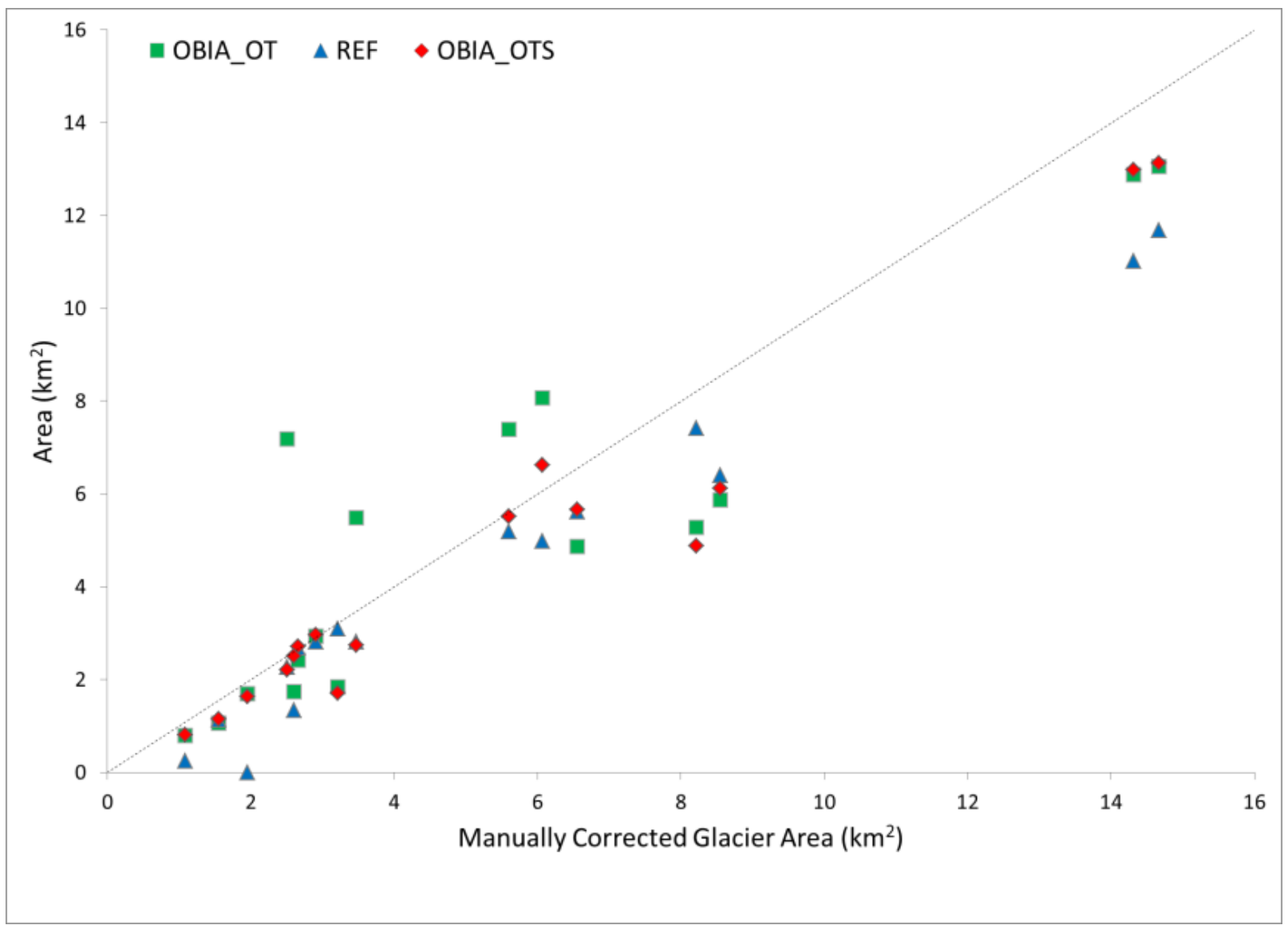

Figure 3: Scatter plot comparing the manually corrected glacier outlines (OBIA_Man) against the OBIA outlines using optical and topographic data (OBIA_OT), the OBIA outlines using optical, topographic and SAR Coherence data (OBIA_OTS) as well as the ICIMOD glacier outlines (ICIMOD) for the debris covered portions of the glaciers in the Manaslu Region. The total glacier area (clean and debris-covered ice) is shown, the clean ice was measured using the OBIA_OT method only.

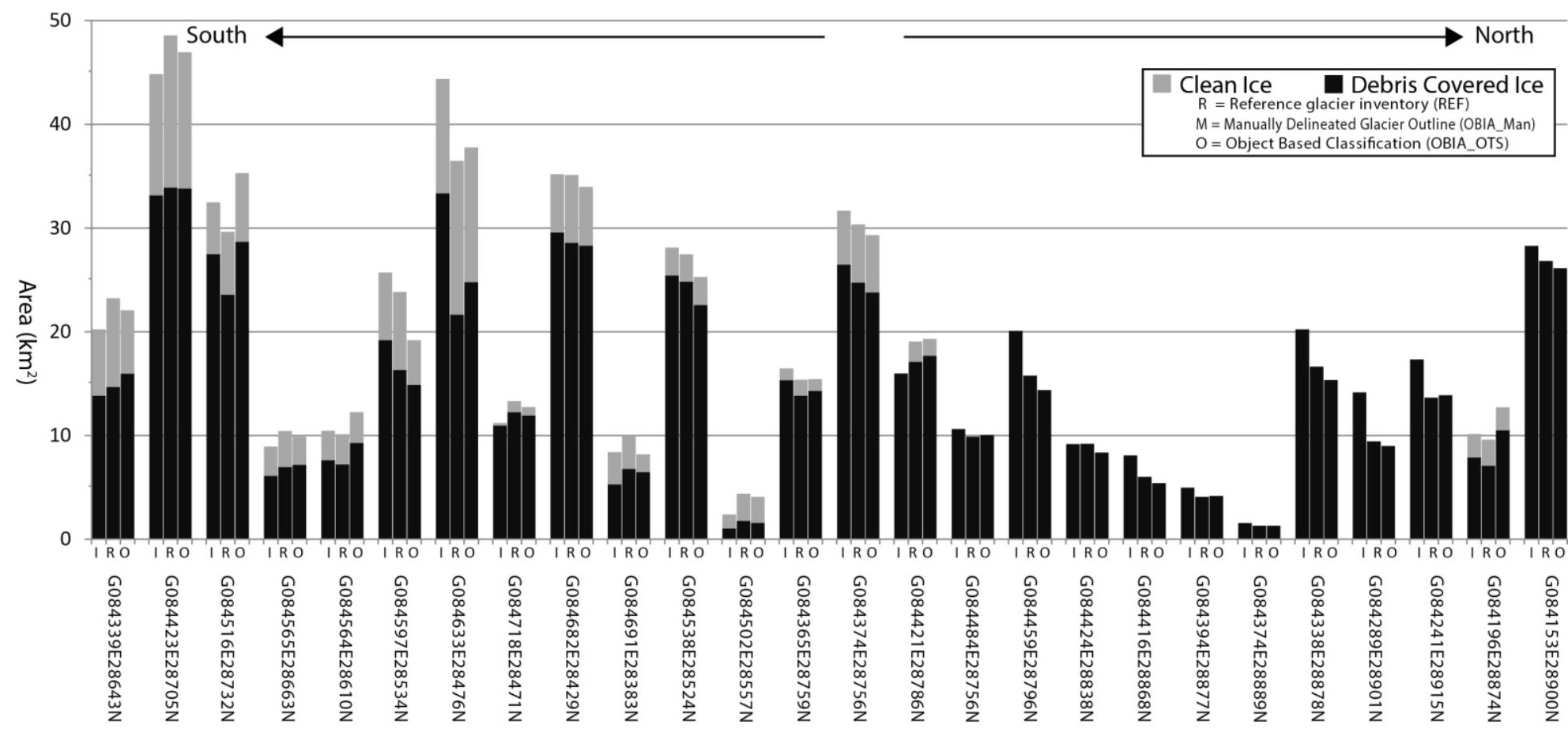

Glacier ID

Figure 4: A Comparison between the measured clean ice areas and debris-covered areas of the glaciers of the Manaslu Region, Nepal. Three areas for each glacier are shown, the reference glacier outlines (REF), OBIA_Man outlines, and the OBIA outlines. The debris covered outlines shown are OBIA_OTS areas while the clean ice areas are OBIA_OT outlines. Clean ice is easier to map automatically and as such OBIA_Man and OBIA_OTS agree 


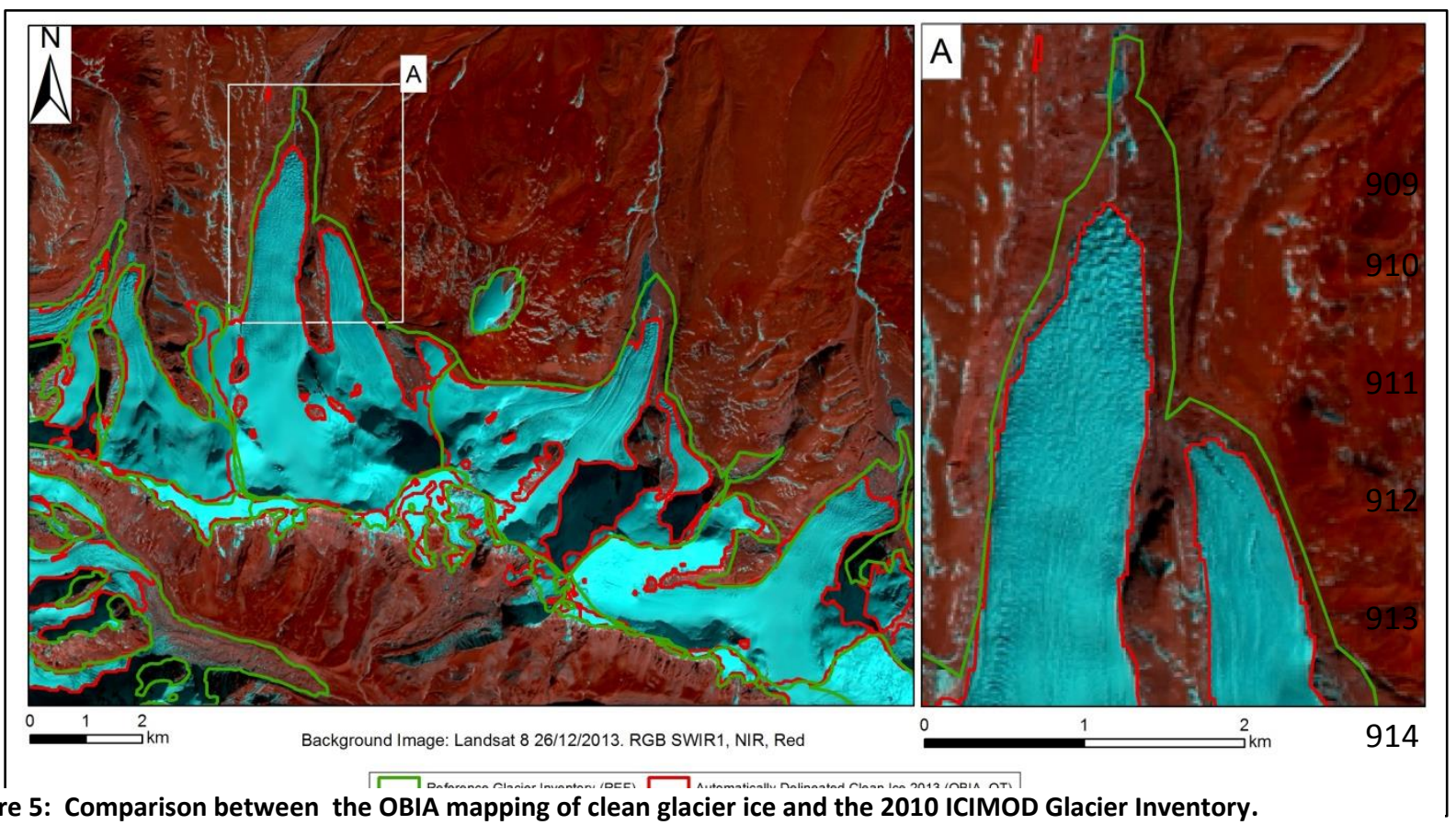

Figure 5: Comparison between the OBIA mapping of clean glacier ice and the 2010 ICIMOD Glacier Inventory.

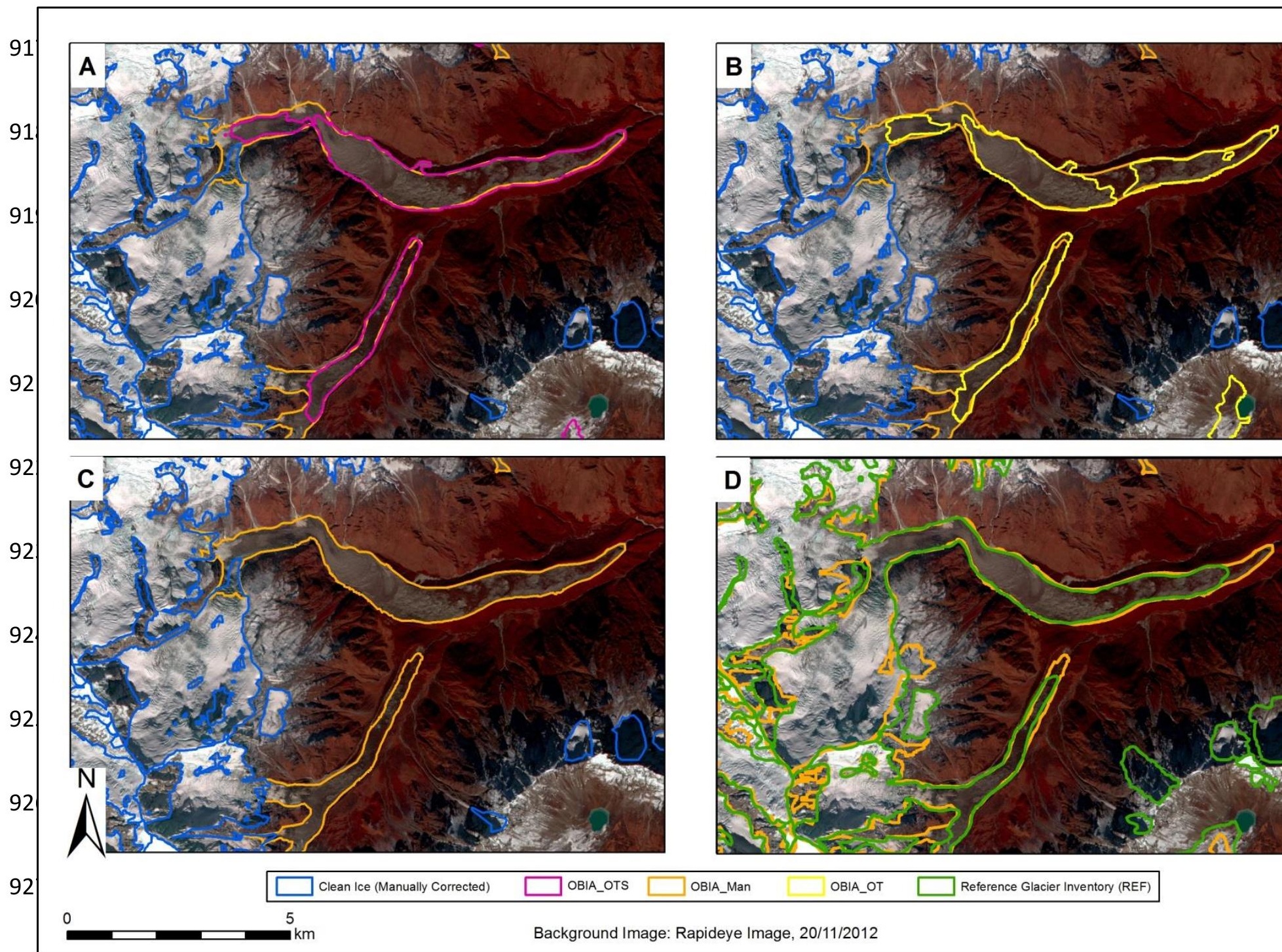

Figure 6: Comparison of the mapping of debris-covered glacier ice. The manually corrected outlines are compared with the OBIA_OTS classification (A), the OBIA_OT classification (B), and the 2010 ICIMOD glacier inventory (C). In addition the OBIA_OTS classification is compared with the 2010 ICIMOD glacier invent (D). Notice how due the OBIA_OT classification is sensitive to the debris lithology, and depicts the glacier as three sections. 


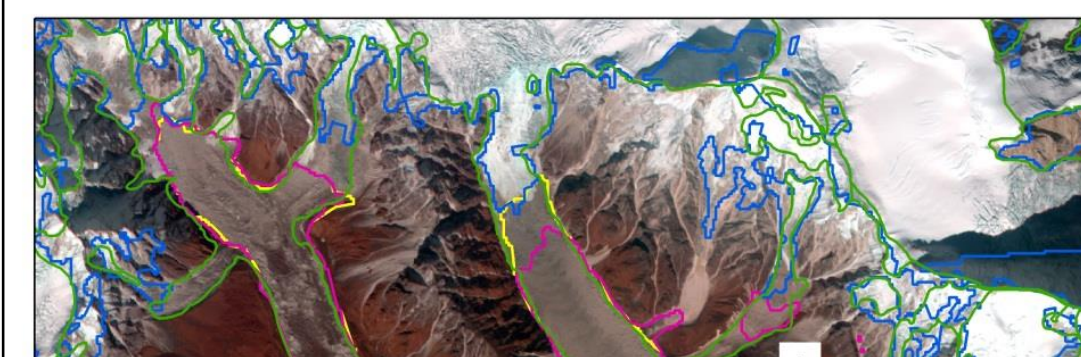

A
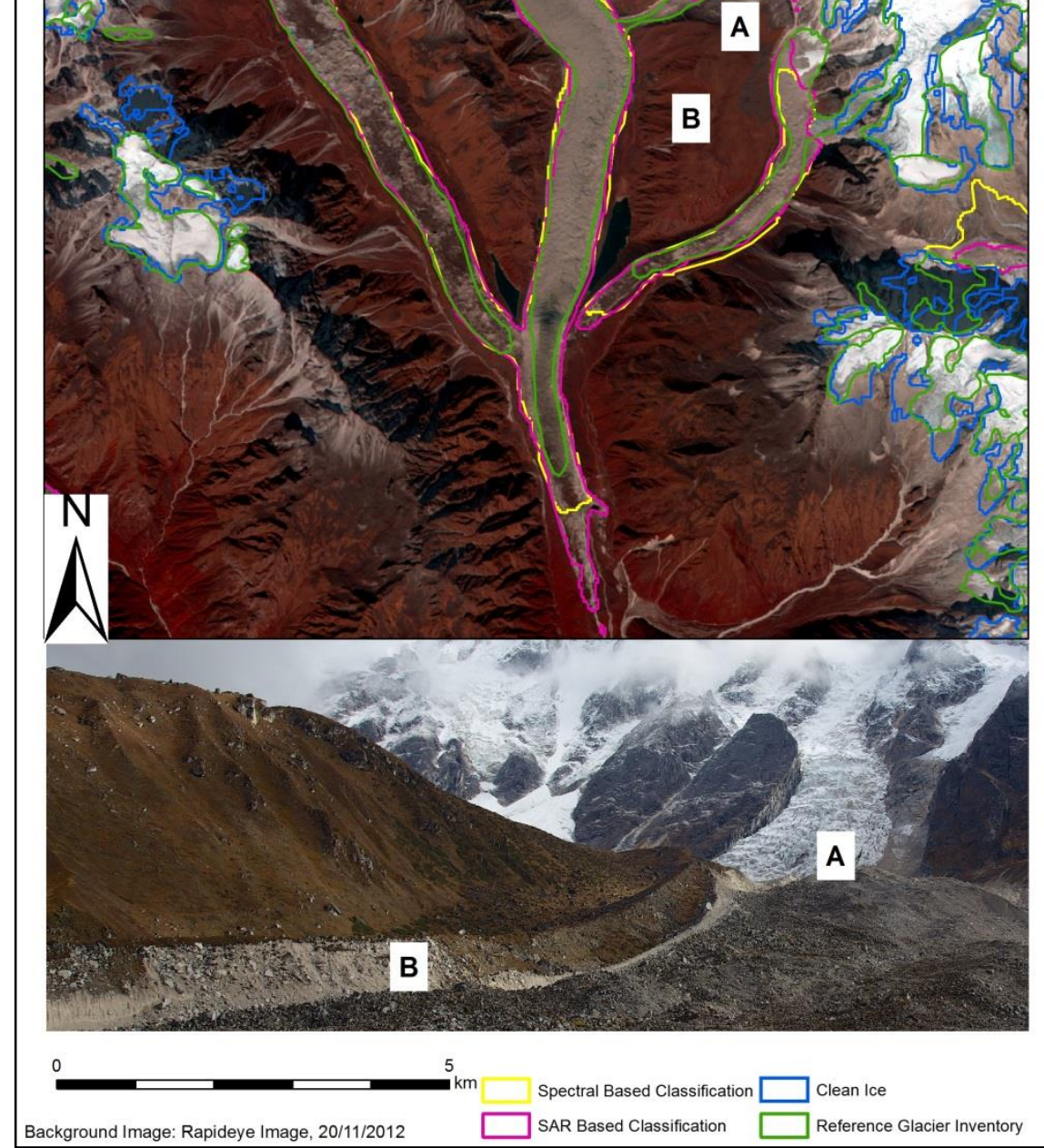

$940 \quad$ Figure 7: The OBIA method struggles most with the steep tributaries (A) where clean ice met debris-covered ice, as well as the extent of the glacier termini. In some cases paraglacial slopes or lateral moraines were also misclassified as debris-covered ice (B). Note in addition the large disparity between the extent of the right hand branch of Ponkar glacier in the OBIA classifications and the ICIMOD glacier inventory. Photo: Pål Ringkjøb Nielsen. 


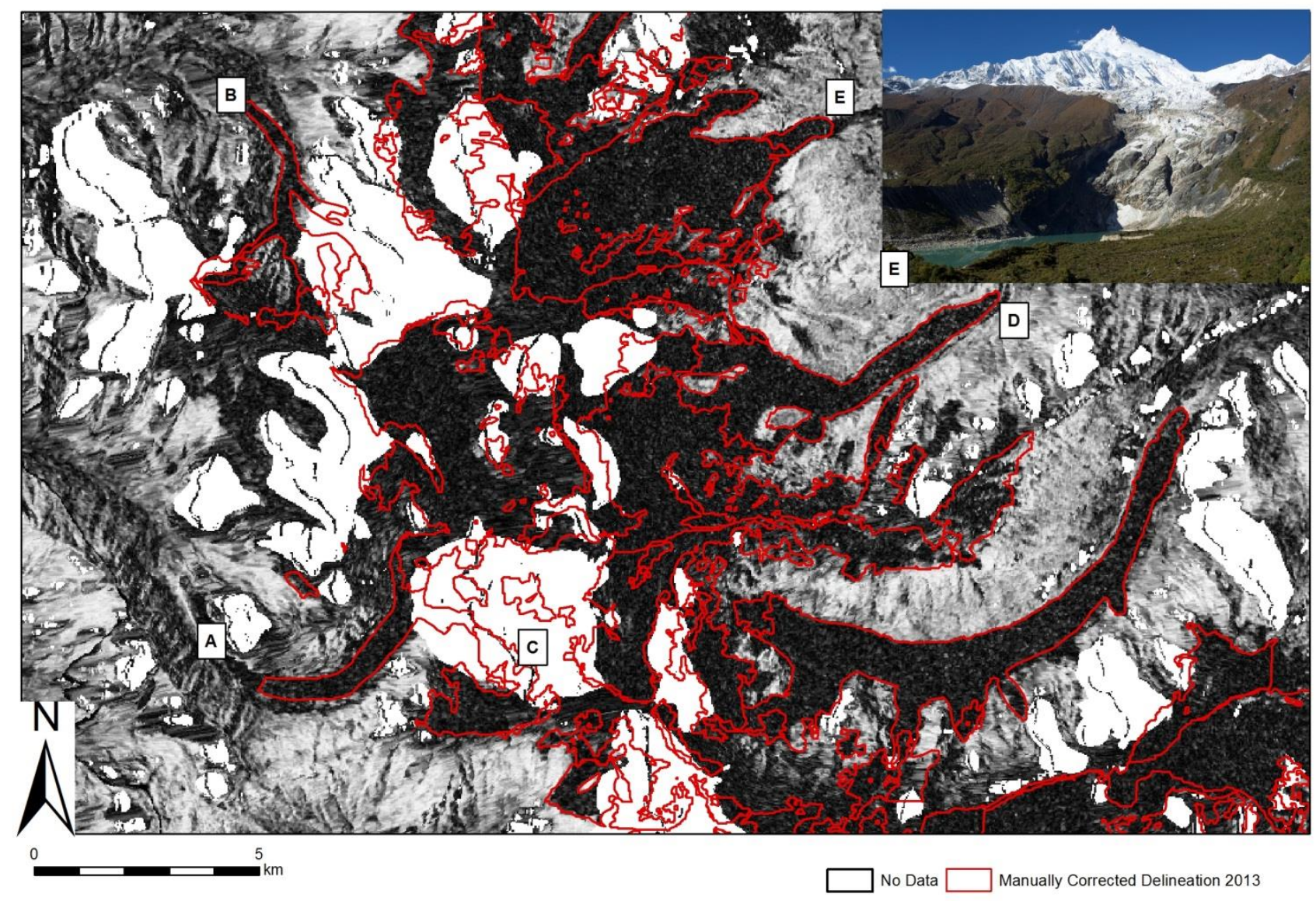

Figure 8: An illustration of where the SAR coherence signal struggled. Dark shades illustrate a loss of coherence, and therefore that 947 motion has occurred or the ground conditions have changed. (A) The loss of coherence over water was indistinguishable from that of glaciers, (B) some steep valleys facing north showed a loss of coherence over the entire valley, making it hard to depict glaciers, (C) some areas no data at all was returned (shown in white) due to the steep topography (D). Many glacier termini however were 948 easy to distinguish based on loss of coherence. E shows Manaslu Glacier, where the loss of coherence data couldn't differentiate between clean ice, very steep proglacial rock and water. 


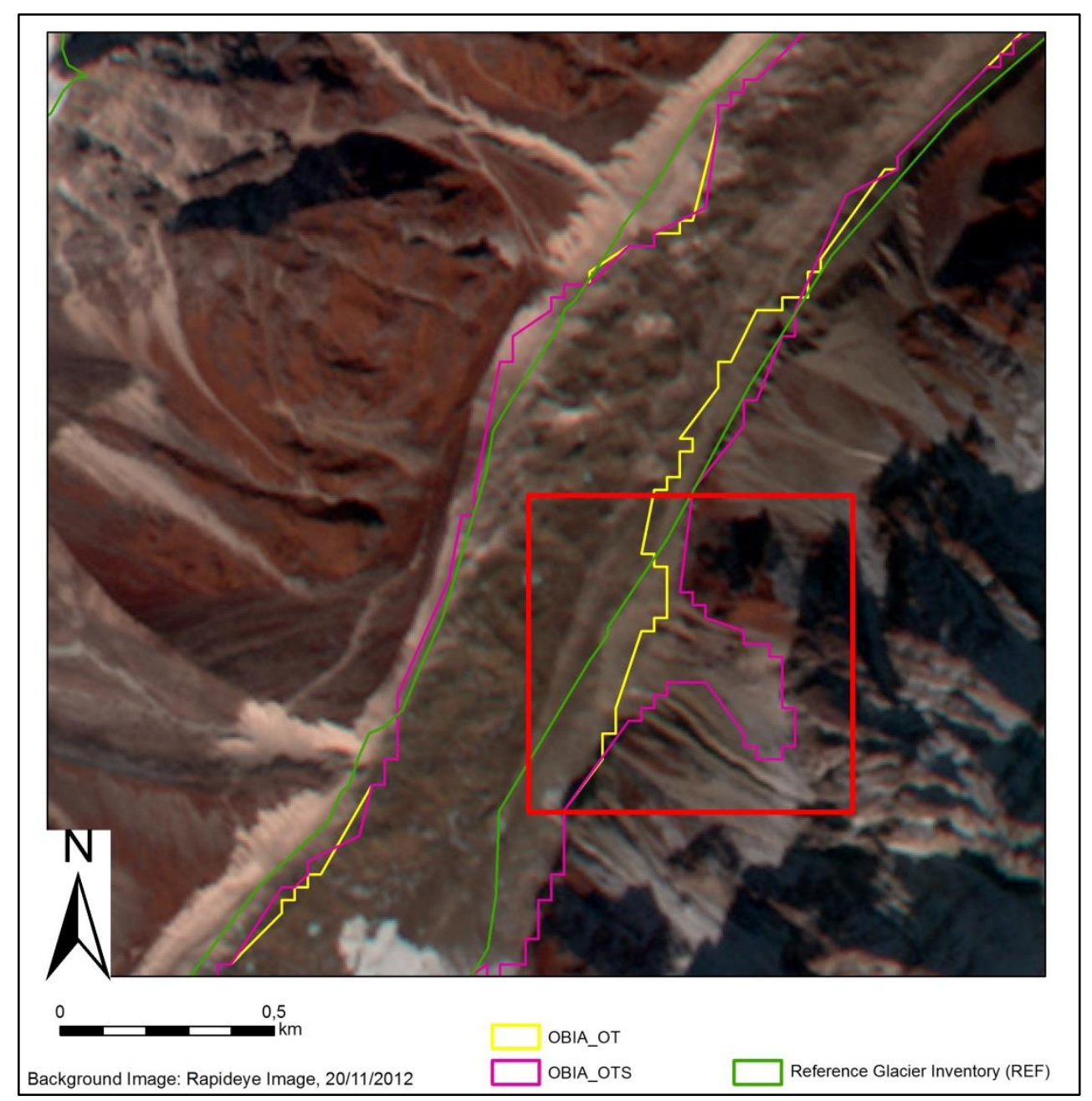

Figure 9: An example from Syancha Glacier (G084564E28610N) of a debris flow flowing onto the glacier (shown in red square). Due to the spectral similarity of the debris-covered ice and the debris flow, as well as a loss of coherence or no SAR data received, the debris flow deposit was misclassified as glacier ice. 